\title{
Syllables without vowels: phonetic and phonological evidence from Tashlhiyt Berber*
}

Rachid Ridouane

Laboratoire de Phonétique et Phonologie (CNRS, Sorbonne Nouvelle)

It has been proposed that Tashlhiyt is a language which allows any segment, including obstruents, to be a syllable nucleus. The most striking and controversial examples taken as arguments in favour of this analysis involve series of words claimed to contain only obstruents. This claim is disputed in some recent work, where it is argued that these consonant sequences contain schwas that can be syllable nuclei. This article presents arguments showing that vowelless syllables do exist in Tashlhiyt, both at the phonetic and phonological levels. Acoustic, fibrescopic and photoelectroglottographic examination of voiceless words (e.g. [tkkststt]) provide evidence that such items lack syllabic vocalic elements. In addition, two types of phonological data, metrics and a spirantisation process, are presented to show that in this language schwa is not a segment which can be independently manipulated by phonological grammar and which can be referred to the syllable structure.

\section{Introduction}

Different approaches to assigning syllable structure have in common the fact that there is a high degree of correlation between the distribution of nuclear and non-nuclear syllable constituents on one hand and the difference between vowels and consonants on the other (Kenstowicz 1994). According to the cross-linguistic syllabification algorithm of Levin (1985), for example, syllable nuclei are projections of vowels. This correlation is not absolute; witness the numerous cases, in different languages, where

* I am indebted to many people for discussion of the ideas and facts presented here: Nick Clements, Lise Crevier-Buchman, François Dell, Cécile Fougeron, Susanne Fuchs, Louis Goldstein, Phil Hoole, Alexis Michaud, Janet Pierrehumbert, Annie Rialland and Donca Steriade, as well as audiences at the Research Laboratory of Electronics (MIT), at Haskins Laboratory (Yale University) and at the 'Phonology Circle' (Linguistic Department, MIT). I am also grateful to the editors, associate editor and three anonymous reviewers for Phonology for their valuable feedback. Thanks are also due to subject consultants for their participation to the phonetic experiments. Any errors or omissions are solely my responsibility. 


\section{Rachid Ridouane}

consonants can occupy syllable-nucleus positions (e.g. the /1/ in English [ba.tl] 'bottle', the $/ \mathrm{r} /$ in Czech [br.no] 'Brno' or the $/ \mathrm{n} /$ in German [ha.bn] 'to have'). Notice, however, that all these nuclear consonants are sonorants. Because of their inherent properties - they are produced with spontaneous vocal fold vibration and display a vowel-like acoustic structure - these segments behave in certain aspects like vowels. The case of languages allowing obstruent-only syllables is highly unusual and far more problematic. At least two such languages have been reported in literature, the Salish language Nuxalk (Bagemihl 1991) and the Berber language Tashlhiyt, spoken in Imdlawn Valley (Dell \& Elmedlaoui 1985, 1988). This paper deals with Tashlhiyt and tackles the issue of the uniqueness of the syllable structure of this language. In particular, it addresses the question of whether there are truly vowelless syllables in Tashlhiyt, as argued by Dell \& Elmedlaoui and disputed in some recent work on the language (Coleman 1996, 1999, 2001, Angoujard 1997, Louali $\&$ Puech 1999, 2000). Both phonetic and phonological arguments are presented to settle this issue. The results provide evidence that there are voiceless obstruent-only syllables lacking vocalic segments that can act as syllable nuclei.

This article is organised as follows. The remainder of this introductory section presents an overview of some phonological and phonetic characteristics of Tashlhiyt ( $\$ 1.1)$ and sets out two competing views of syllabification in this language $(\$ 1.2)$. $\S 2$ presents the phonetic $(\$ 2.1)$ and phonological (\$2.2) data examined to determine whether syllables lacking schwas exist at the level of phonetic and phonological representations. The implications of the results for the general issue of the nature of the syllable are briefly outlined in the general discussion $(\$ 3)$.

\subsection{Tashlhiyt: a Berber language}

Berber is an Afro-Asiatic language spoken in large parts of North Africa, mainly in Morocco and Algeria. Galand (1988: 209) gives a conservative estimate of 15 million for the total number of Berber speakers in 1983. The three main Berber dialects spoken in Morocco are: Tarifit (spoken in northern Morocco), Tamazight (spoken in the Middle Atlas) and Tashlhiyt (spoken in southern Morocco). Tashlhiyt, the variety investigated here, is sufficiently homogeneous for all native speakers, who numbered an estimated 3 million at the beginning of the nineties (Chaker 1992), to communicate without difficulty. ${ }^{1}$ There is nonetheless some subdialectal variation. Boukous (1994) shows that Tashlhiyt can be

1 For references to work on Tashlhiyt, see Chaker (1992, 1994) and Dell \& Elmedlaoui (2002: 5-8). For the historical phonology of this language, see Elmedlaoui (2000) and the references therein. For other phonetic aspects, see Ouakrim (1993), Ridouane (2003, 2007), Ridouane et al. (2006) and Ridouane et al. (2007). Work on stress and intonation in Tashlhiyt is still needed. According to Dell \& Elmedlaoui's (1985) preliminary observations, stress or accent seems to be a property of units larger than words. The main pitch event in an intonational phrase occurs on the penultimate or antepenultimate sonorant syllable nucleus. 
subdivided into three main subsystems, each named according to one of its salient phonetic/phonological properties: (a) the 'occlusive' subsystem, spoken in Agadir and its suburbs, (b) the 'fricative' subsystem, spoken mainly in the High Atlas area, which spirantises the non-coronal obstruents / b k g/ in some contexts, and (c) the 'sibilant' subsystem, spoken in the Anti-Atlas area, where $/ \mathrm{t} /$ and $/ \mathrm{d} /$ are realised in some contexts as [s] and $[z]$ respectively. These three varieties, which share the same phonemic system, are examined in this study.

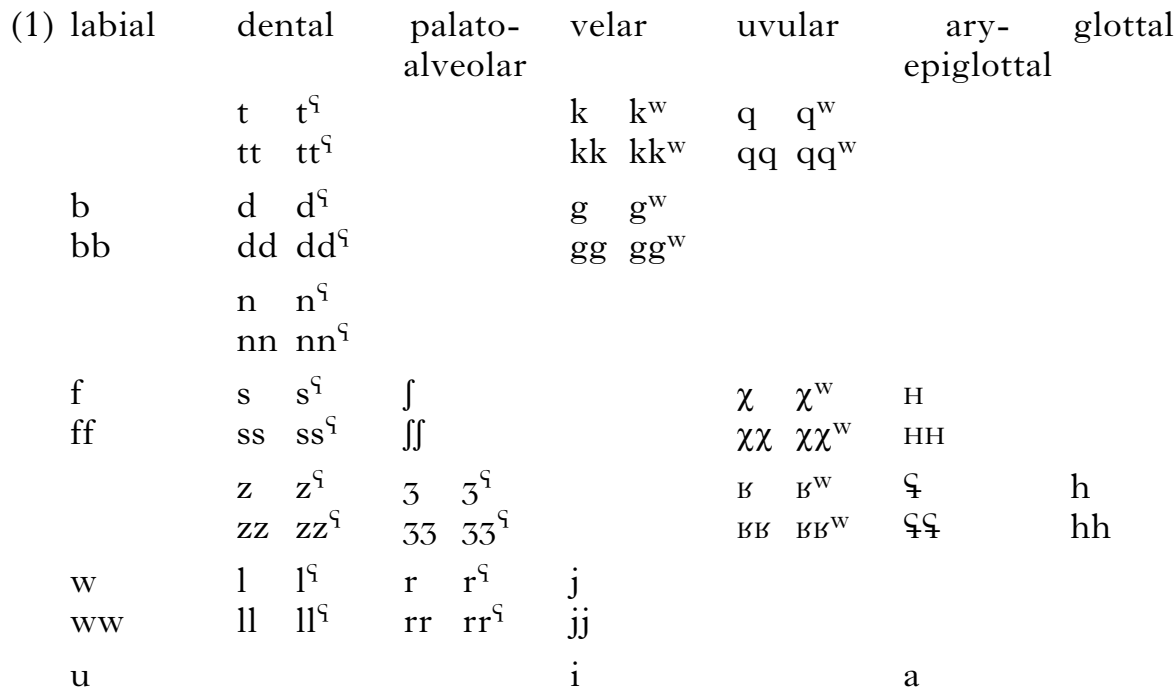

Except for the vowels, each phoneme in (1) has a geminate counterpart in the underlying representations. ${ }^{2}$ The distinction between single and geminate consonants is attested in medial position, as well as in absolute initial and final positions (e.g. /tili/ 'ewe' vs. /ttili/ 'have (IMP)', /fi=t/ 'give it (MASC)' $v s$. /fi=tt/ ' give it (FEM)'). ${ }^{3}$ There are numerous other positions which a geminate can occupy within a word. It can be preceded or followed by one or more consonants (e.g. /t-ss- $\chi$ si-t=stt/ 'you switched it off'). A word may contain only one geminate consonant (e.g. / $\iint /$ 'eat', /kk/ 'take (the road)'). In addition to geminates, Tashlhiyt has a set of dorsopharyngealised phonemes, all of which are coronal. At the phonetic level, dorsopharyngealised phonemes spread emphasis to all the other segments present in a word or even a sequence of words (Elmedlaoui 1985, Boukous

2 Note, however, that geminate counterparts of aryepiglottals and laryngeals are very rare (see Ridouane 2003).

3 Forms enclosed between slant brackets are 'underlying forms' (morphemic transcriptions). Those not enclosed between slants are intended to represent phonetic representations given in a broad transcription. Hyphens mark morphological boundaries inside words, while equal signs mark boundaries between clitics and their hosts. Nuclei consonants are underlined, and periods are used to mark syllable boundaries. 


\section{Rachid Ridouane}

1987). For instance, in /t-zd'ar-t/ 'you are able', which contains only one emphatic phoneme, the whole word is emphatic![tzdart] (such words will be henceforth preceded by an exclamation mark). So-called 'pharyngeal' fricatives also exist in Tashlhiyt. But, as shown in Ridouane (2003), these segments are epiglottals or aryepiglottals rather than pharyngeals, transcribed here as $/ \mathrm{H} /$ and $/ \Varangle /$ for the voiceless and the voiced fricatives respectively.

\subsection{The syllable structure of Tashlhiyt: two competing views}

The syllable structure of Tashlhiyt was initially described by Dell \& Elmedlaoui (1985, 1988), and expanded in Dell \& Elmedlaoui (2002). According to these authors, there are in this language, in addition to the more conventional syllable types $\mathrm{CV}$ and $\mathrm{CVC}$, syllables which consist of only consonants, $\mathrm{CC}$ and $\mathrm{CCC}$ (where the second $\mathrm{C}$ is the nucleus). In this analysis, syllables of the shape $[\mathrm{t} \underline{\mathrm{k}} \mathrm{k} \underline{\mathrm{d}} \mathrm{t} \underline{\mathrm{k}}]$ are common, as in (2).

(2)

nucleus type
vowel
nasal
liquid
voiced fricative
voiceless fricative
voiced stop
voiceless stop

\begin{tabular}{|c|c|}
\hline & morphology \\
\hline ts.ti & t-sti \\
\hline i. $\chi$ ng & $i-\chi n g$ \\
\hline r.gls & rgl-s \\
\hline ts.$b \underline{b} t$ & $t-s b b-t$ \\
\hline ts.ti & t-sti \\
\hline $\mathrm{i} \underline{\underline{j} . \mathrm{kd}}$ & i-fkd \\
\hline ta.zn. $\mathrm{k}^{\mathrm{w}} \underline{\mathrm{tt}}$ & $\mathrm{t}-\mathrm{a}-\mathrm{znk} \mathrm{k}^{\mathrm{w}} \mathrm{d}-\mathrm{t}$ \\
\hline
\end{tabular}

\author{
'she has selected' \\ 'he has strangled' \\ 'I have locked' \\ 'you (sG) have painted' \\ 'she has selected' \\ 'broken branch' \\ 'female gazelle'
}

The Tashlhiyt facts, cited as a typologically unique phenomenon (Zec 1995), have served as a testing ground for important theoretical proposals (Hyman 1985, Clements 1997), and have become something of a cause célébre, especially since their use by Prince \& Smolensky (1993) as a clinching argument in favour of Optimality Theory (Nathan 2004). Dell \& Elmedlaoui's account of Tashlhiyt syllable structure revolves around two mutually independent claims, what they call the 'sonority-driven syllabification' thesis and the 'licit consonant nuclei' thesis.

The first thesis states that all the information relevant for predicting the syllable structure of an expression resides in the consonants and the full vowels contained in that expression. In the competition for the status of syllable nucleus, more sonorous segments are favoured over their less sonorous neighbours. The sonority scale proposed reflects a rather typical classification of speech sounds, where the sonority of a segment is highly correlated with the relative degree of openness of the vocal tract (vocal fold vibration is another physical criterion distinguishing voiced and voiceless obstruents; voiced obstruents being more sonorous). The low vowel $/ \mathrm{a} /$ is the most open, and hence the most sonorous. Non-low vowels are more sonorous than consonants, and fricatives are more sonorous than stops. The selection of syllabic nuclei and the core syllables (onset-nucleus) is 
reached through a syllable-construction procedure that descends through the sonority scale from highest to lowest. ${ }^{4}$ A form of the type /t-sti/ 'she has selected' is thus syllabified [t. /i/ being the syllabic nuclei. As in various other languages, the sonority requirement has to be compatible with other requirements, such as the prohibition against onsetless syllables or complex onsets and codas. Consider, for example, the final syllable of the form /i-saUl/ 'he talked', which is parsed as [i.sa.wl]. The adjacency between two vowels inside a word (i.e. $/ a /$ and $/ U /$ ) is prohibited. The high vocoid $/ U /$, which surfaces as a semivowel, occupies the onset of the syllable, and the liquid, though less sonorous, is the nucleus. If prohibition against onsetless syllables is not granted priority over the sonority requirement, we incorrectly form a syllable nucleus on $/ \mathrm{U} /$ and derive *[i.sa.ul] instead of [i.sa.wl]. Evidence from various sources converges in support of the 'sonority-driven syllabification' thesis. First, we can gain insight into various morphological regularities (e.g. length alternations in the causative prefix and onset gemination in the formation of imperfective stems) by assuming the proposed syllabification of consonant sequences. ${ }^{5}$ Second, various generalisations concerning the form of Tashlhiyt syllables and the distribution of their nuclei are independently motivated constraints of syllable theory, e.g. the onset constraint, constraints against complex codas and onsets, and constraints on syllable nuclei and margins (Zec 1988, 1995, Prince \& Smolensky 1993, Clements 1997). Probably the richest source of evidence for the syllabification proposed for Tashlhiyt is provided by native speakers' judgements about syllable count. These involve both native linguist intuitions (e.g. those of Elmedlaoui 1985, Boukous 1987, Jebbour 1995 , as well as the present author) and well-formedness in versification (Dell \& Elmedlaoui 2002; see also below). ${ }^{6}$

I return now to the second thesis, which is the main concern of this paper and by far the most disputed component in Dell \& Elmedlaoui's account of Tashlhiyt syllable structure. The 'licit consonantal nuclei' thesis states that the only surface vowels in Tashlhiyt are realisations of /a $\mathrm{i} \mathrm{u} /$, and that, in the absence of one of these three full vowels, any consonant, even a voiceless stop, can act as a syllable peak. The most striking and controversial examples taken as arguments in favour of this thesis involve words containing long consonantal clusters (e.g. [tg.nu] 'we slept', [t.. .r r t ] 'you woodened', [t…dg] 'it is wet'). Such consonantal clusters are claimed to surface with no schwas that can act as

${ }^{4}$ Dell \& Elmedlaoui (2002) adopt a constraint-based approach in their discussion of syllabification in Tashlhiyt and Moroccan Arabic. Their 1985 and 1988 publications rely on sequential derivations. Rules and constraints are used by the authors as mere descriptive tools.

5 See Dell \& Elmedlaoui (2002: 115-134) for a detailed discussion of these morphological regularities.

6 The syllabification of Tashlhiyt items presented in this work reflects my own native speaker intuitions. Except for items containing initial or final geminates, these intuitions are rather straightforward, both about the number of syllables and about which consonants are syllabic nuclei (see Table I). 


\section{Rachid Ridouane}

syllable peaks, though they may contain what Dell \& Elmedlaoui view as mere transitional vocoids, which do not play any role in syllable structure. In their view, the vocoid between $/ \mathrm{t} /$ and $/ \mathrm{g} /$ displayed in Fig. 2 below is an intrusive vocoid, which corresponds to a lag between the offset of the closure of $/ \mathrm{t} /$ and the onset of the closure of $/ \mathrm{g} /$, and its voicing is an extension of that of $/ \mathrm{g} /$. This claim is not based on any experimental phonetic data, however. It reflects the perceptions of one of the authors (Dell), who does not speak the language. The other author (Elmedlaoui), who is a native speaker, is in most cases unaware of their presence in his speech.

Several authors have challenged this analysis, and have tried to demonstrate that the syllable structure of Tashlhiyt can be analysed in conformity with the syllable structure of the majority of the world's languages (e.g. Coleman 1996, 1999, 2001, Angoujard 1997, Louali \& Puech 1999, 2000). On the basis of his belief that all words have syllables and all syllables have vowels in all languages, Coleman (2001) proposes what he calls the 'coproduction analysis of syllabic consonants', and interprets Dell \& Elmedlaoui's syllabic consonant as a sequence of schwa + consonant. More specifically, he argues that the schwa realised between $/ t /$ and $\mathrm{lg} /$ in $/$ tgnu/ is an epenthetic segment, introduced by the phonological component to repair syllable structure. In his model, such epenthetic schwas are expected to occur in the phonology, in any syllable nucleus that is not filled by one of the lexical vowels $/ \mathrm{a} \mathrm{i} \mathrm{u} /$. With the exception of those occurring next to $/ \mathrm{r} /$, all these schwas are reflexes of syllable nuclei. ${ }^{7}$ Importantly, while rejecting Dell \& Elmedlaoui's 'licit consonantal nuclei', Coleman adopts the main view behind the sonority-driven syllabification thesis, arguing that more sonorous consonants are favoured over less sonorous ones in determining the location of these epenthetic vowels. These schwas are argued to be either overtly realised in the signal, or else phonetically overlapped by neighbouring consonants. Among the arguments presented by Coleman (2001) in support of this analysis, the most important for our purposes in this paper are his acoustic measurements. ${ }^{8}$ His data consists of recordings of the Tashlhiyt forms in Dell \& Elmedlaoui (1985), produced by one subject (Elmedlaoui). Coleman used signal detection theory (Macmillan \& Creelman 1991) to compare the goodness-of-fit between the observed distribution of epenthetic vowels in Elmedlaoui's speech and their expected occurrence according both to his model and to Dell \& Elmedlaoui's analysis. Results of his acoustic analysis showed that epenthetic vowels occurred in $40 \%$ of the subject's realisations. The overall goodness-of-fit, as indicated by d' statistics, showed that Coleman's model is only slightly better in predicting the occurrence

7 In Coleman's model, these schwa-like vowels occurring in the phonetics reflect the instances where the taps of the alveolar trill are almost always accompanied by short, central vocoids.

8 The phonological arguments given to support this view are refuted by Dell \& Elmedlaoui (1996) in their reply to Coleman's paper in the same volume. See also Dell \& Elmedlaoui (2002: 178-187). 
of schwa vowels $\left(d^{\prime}=4 \cdot 74\right.$ as compared to $\left.d^{\prime}=4 \cdot 34\right)$. Coleman, however, thinks his model should be preferred. In particular, he observed that pronunciations by Elmedlaoui of some words are highly problematic for Dell \& Elmedlaoui's model. This is the case for the form $/ \mathrm{t}-\mathrm{mzH} /$ 'she jested', produced with a schwa in word-final position (see Louali \& Puech 2000, who also observed word-final schwas in the production of some Tashlhiyt speakers). This schwa cannot be considered as a mere transition between consonants, since it occurs in word-final position preceded by a voiceless consonant. According to Coleman, this occurrence is consistent with the analysis of stem-final $/ \mathrm{H} /$ as a syllable onset followed by a schwa nucleus (i.e. [təmz.Hə]).

To sum up, Dell \& Elmedlaoui presented various convincing arguments in support of a rather surprising empirical finding: in Tashlhiyt a sequence of the type [tk] is a well-formed onset-nucleus syllable. But they provided no phonetic experimental evidence showing that such clusters indeed lack a schwa that can act as a syllable peak. Impressionistic phonetic observations have some value in studies of syllabification, but cannot be relied on in highly complicated cases like the ones considered here. Coleman, on the other hand, presents some acoustic data to back up his claim that the phonological component inserts schwa in such clusters in order to repair syllable structure. His acoustic data, however, are very limited, and concern only the productions of one subject, who was certainly aware of the object of the study. A critical question is thus far from being clearly settled: does Tashlhiyt contain long vowelless clusters with no vocalic element that can act syllabically? One way of answering this question is to determine whether Tashlhiyt schwas, if any, result from phonological vowel epenthesis or whether they are purely intrusive phonetic-level phenomenon of no structural relevance.

\section{The status of schwa in Tashlhiyt phonetics and phonology}

Though both schwas resulting from phonological insertion and intrusive phonetic-level schwas are often labelled 'epenthetic' (see Hall 2003 and references therein), it is important to draw a clear distinction between the two. ${ }^{9}$ As extensively discussed by Hall $(2003,2006)$, these two vocoids differ in several respects. The first is related to their phonetic manifestation. While intrusive vowels have a very limited distribution, epenthetic vowels can surface within any consonant cluster, regardless of its phonetic make-up. In Mono, for example, intrusive vowels surface only next to sonorants, while epenthetic vowels can copy over any consonant

9 Salish languages have both types of schwas. Intrusive schwas are transitional elements which may be present in the acoustic signal but which cannot be manipulated by phonological grammar. Epenthetic schwas, on the other, are present phonologically, as well as acoustically and perceptually (Shahin \& Blake 2004, and references therein). 


\section{Rachid Ridouane}

(Hall 2006). The second difference is related to what they can do within a syllable. Unlike epenthetic vowels, intrusive vowels cannot act as syllable peaks and thus create new syllables. The non-syllabicity of intrusive vowels follows from the third characteristic of these elements. Unlike epenthetic vowels, intrusive vowels do not correspond to independent segments, which a rule or a constraint can refer to. These three phonetic and phonological differences can be used as diagnostics to test for the status of Tashlhiyt schwa. The phonetic data to be considered here consist of words containing underlyingly only voiceless stops and fricatives. The aim is to determine whether these words surface with or without schwa. Two types of phonological data, metrics and a spirantisation process, are examined in order to determine whether schwa corresponds to a segment which can be independently manipulated by phonological grammar and which the syllable structure can refer to.

\subsection{Phonetic data}

In Tashlhiyt, roots and affixes may consist underlyingly of voiceless obstruents only. When combined, they can give rise to words and sentences containing only voiceless stops and fricatives (e.g. / $\mathrm{t}-\int \mathrm{tf}-\mathrm{t} /$ ' you crushed', /t-kks-t/ 'you took off', / $t-\iint-t=s t t /$ 'you ate it (FEM)'). These forms conform in every respect to the structure of other lexical words in Tashlhiyt, and cannot be viewed as lexically or morphologically marginal. ${ }^{10}$ In addition to being an interesting subject for phonetic investigation, these data are of critical importance in evaluating the different analyses of Tashlhiyt syllable structure. If schwas in Tashlhiyt were mere intrusive elements which copy over voiced consonants only, as Dell \& Elmedlaoui claim, then these words would be expected to surface as genuinely voiceless, lacking schwa. On the other hand, if these words contained epenthetic schwa, as Coleman (2001) claims, this would mean that the phonetic representation of Tashlhiyt contains a fourth vowel, in addition to the realisations of /a i u/, that could act as a syllable peak. A priori, then, in Coleman's view, a word consisting underlyingly of voiceless obstruents only would be expected to surface with voiced schwa (through schwa epenthesis), and/or with (partially) devoiced schwa (through schwa epenthesis followed by contextual devoicing). ${ }^{11}$ The phonetic experiments were conducted to test

10 To provide an estimate of the frequency of vowelless words, I made use of a collection of 20 texts published in Podeur (1995). Results show that these texts contain 5700 syntactic words, 1271 of which are composed of consonants only, and 451 of which are composed of voiceless obstruents only. In other words, voiceless syntactic words occur eight times in every 100 words. The productivity of this phenomenon is, for example, higher than that of the two largely studied phenomena of liaison and enchainement in French, which have a productivity of $6 \%$, according to Fougeron \& Delais-Roussarie (2004).

11 A proponent of Coleman's model might also claim that there is a third possible (absence of) realisation: schwas being 'hidden' by the surrounding consonants in both syllables. It is not clear, however, how this would support the schwa-nucleus theory: can a hidden segment act phonologically? This is discussed in $\S 2.2$. 


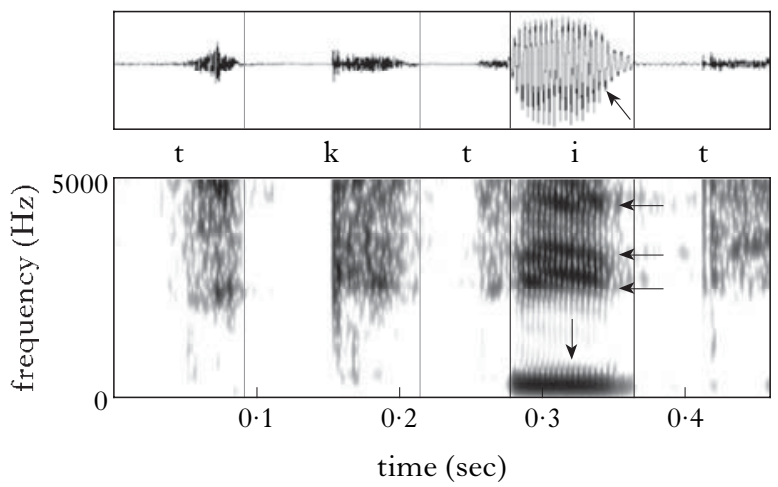

Figure 1

Acoustic waveform and spectrogram of [tktit] 'you remembered', as realised by $\mathrm{F} 1$ in isolation. Arrows mark characteristics of a high vowel: periodic wave, formant structure and voicing bar.

for these two possible realisations. The 'voiced schwa' and the 'devoiced schwa' realisations are tested in $\S 2.1 .1$ and 2.1.2 respectively.

2.1.1 The 'voiced-schwa' realisation. Acoustic and fibrescopic data were used to test for the presence of voiced schwas within underlyingly voiceless obstruent-only words. The aim of the acoustic data was to search for cues for the presence or absence of voiced schwa in the waveforms and spectrograms of these items. The fibrescopic examination was performed as an additional experiment, with the goal of providing direct evidence for the presence or absence of vocal fold vibrations during these forms.

2.1.1.1 Acoustics. Figures 1-4 give illustrations of consonant clusters surfacing with or without a vowel, and provide the labelling used to detect the presence of a voiced schwa. Figure 1 illustrates the realisation of the full vowel /i/ in the context of voiceless obstruents ([tktit] 'you remembered'). This vowel is voiced, and displays periodic wave and the formant structure of a high unrounded vowel. Figure 2 illustrates the realisation of a voiced schwa within a cluster containing a voiced consonant ([tgnu] 'she sewed'). Figure 3 illustrates the realisation of a voiced schwa in the context of voiceless obstruents ([t $\mathrm{t} t \mathrm{tft}]$ ' you crushed'). As is the case for full vowels, this schwa also displays a period of voicing, a periodic wave and a formant structure. Figure 4, on the other hand, illustrates the realisation of a voiceless word ([tftktstt] 'you sprained it'). No voicing, formant structure or periodic wave is visible on the waveform or the spectrogram. Such items are considered here as having no surface voiced schwa.

Data and subjects. Twenty-four phonological words, composed of voiceless obstruents only, were used as data. These forms, listed in 


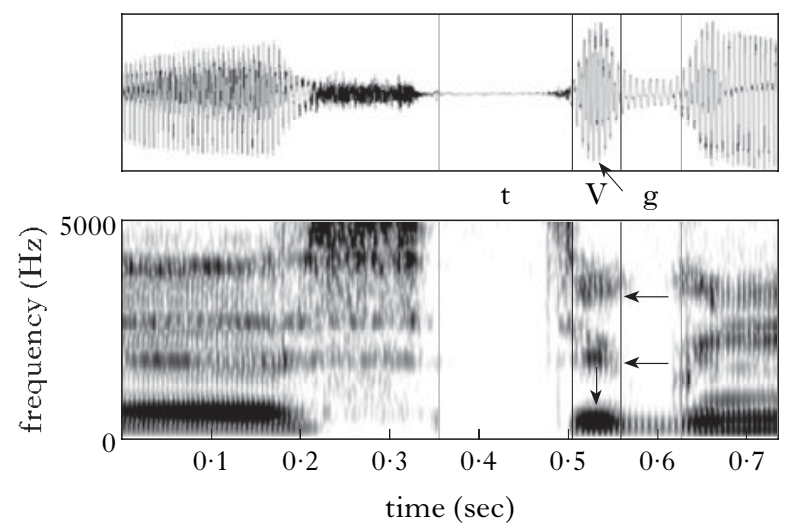

Figure 2

Acoustic waveform and spectrogram illustrating the production of a voiced vocoid within an underlying obstruent cluster (example taken from the sentence innajas tgnu jat twalt 'he told him he sewed once', as realised by M1). The characteristics marked by the arrows include periodic wave, formant structure and voicing bar.

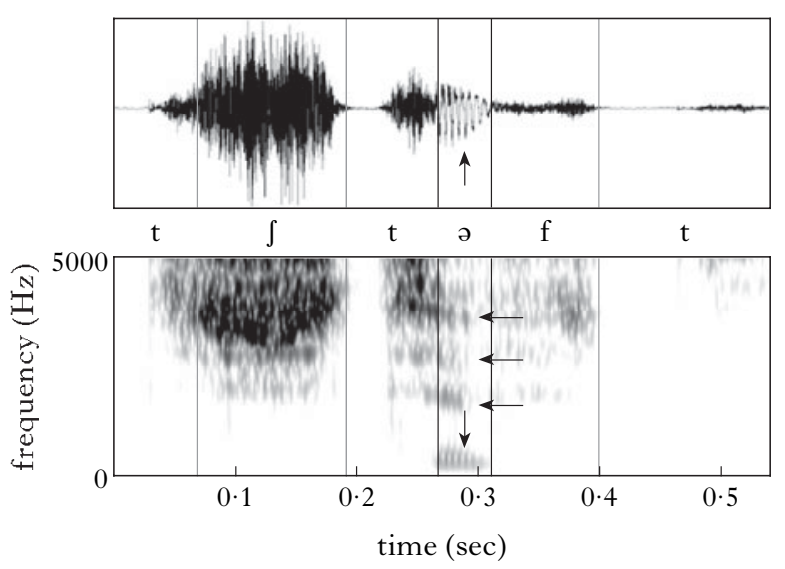

Figure 3

Acoustic waveform and spectrogram of [t]təft] 'you crushed', as realised by M1, with an internal voiced schwa. Arrows mark the acoustic characteristics of this vowel (i.e. periodic wave, formant structure and voicing bar).

Table I, are all widely used verbs consisting of one to four syllables. Forty additional verbs, containing vowels and voiced consonants, were also recorded. These additional items were used to ensure that subjects were unaware of the purpose of the study (some of these items, presented in Appendix A, will be referred to in §2.1.2). 


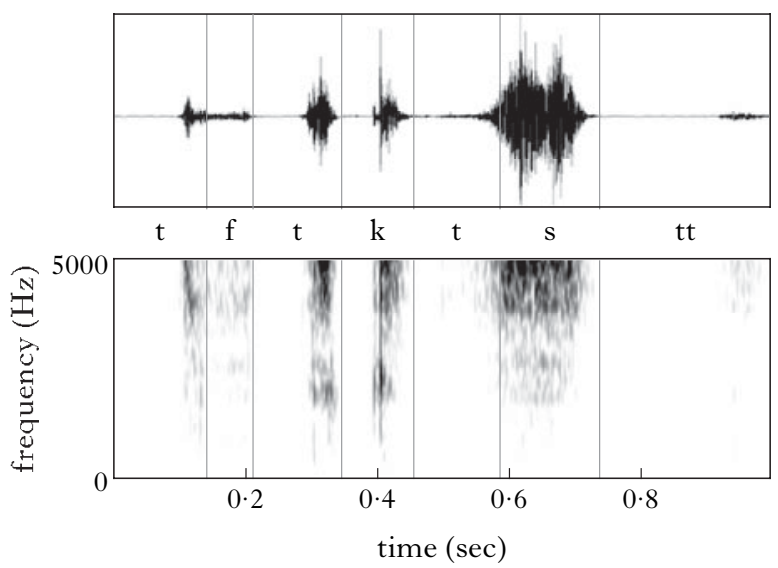

Figure 4

Acoustic waveform and spectrogram of [tftktstt] 'you sprained it (FEM)', as realised by M1 in isolation, showing the absence of acoustic characteristics of a voiced vowel.

Six native speakers of Tashlhiyt - four male and two female (henceforth M1, M2, M3, M4, F1, F2), with no report of speech disordersparticipated in the experiment. They all had a university education, and had learned Classical Arabic and French at school. All the six subjects spoke Moroccan Arabic, a non-taught national language. The subjects were selected from various Tashlhiyt regions, so as to include speakers from the three subdialects presented above (see Table II). The goal was to assess the cross-dialectal validity of the observations, and to determine whether voiceless, vowelless words are attested in the three subdialects, or rather confined to small areas such as the one analysed by Dell \& Elmedlaoui (the Tashlhiyt variety spoken in Imdlawn valley). ${ }^{12}$

The recordings of four of the subjects were made in a quiet room in the Laboratoire de Phonétique et Phonologie in Paris; the remaining two were recorded in a quiet room in their homes. The stimuli were written in the Roman alphabet, ${ }^{13}$ and were presented on six differently randomised lists on paper, corresponding to six repetitions (three in isolation (as one-word phrases) and three in the frame sentence inna jas _ jat twalt 'he told him _once'). Subjects were asked to familiarise themselves with items and to read each form in isolation and in the frame sentence for practice before recording began. They were asked to pronounce each sentence and isolated item at normal utterance speed. When they mispronounced a word or sentence, they were asked to repeat the stimulus item from the

12 This variety of 'Tashlhiyt belongs to the 'fricative' dialect.

13 The segments $/ \int \chi \mathrm{H} /$ were transcribed as $c x h$ respectively, following the traditional transcription of Berber (Elmedlaoui 1999). Capitalisation was used to transcribe the phonemic dorso-pharyngealisation of dental consonants (e.g. $T$ for $/ \mathrm{t}^{\mathrm{\complement}} /$ ). 


\begin{tabular}{|c|c|c|c|c|}
\hline & & & $\begin{array}{c}\text { number of } \\
\text { syllables }\end{array}$ & $\begin{array}{l}\text { syllable } \\
\text { parsing }\end{array}$ \\
\hline 1 & $\mathrm{fk}$ & 'give’ & 1 & $\underline{\mathrm{fk}}$ \\
\hline 2 & ks & 'feed on' & 1 & $\mathrm{k} \underline{\mathrm{s}}$ \\
\hline 3 & $\mathrm{ks}=\mathrm{t}$ & 'feed it on' & 1 & ks $\underline{t}$ \\
\hline 4 & kks & 'take off' & 1 & ? kks \\
\hline 5 & tfss & 'she is quiet' & 1 & ?t \\
\hline 6 & $\mathrm{kks}=\mathrm{tt}$ & 'take it off' & 1 & ?kkstt \\
\hline 7 & $\mathrm{fk}=\mathrm{t}$ & 'give it' & 2 & $\underline{f} \cdot \mathrm{kt}$ \\
\hline 8 & $s \chi f$ & 'fade away' & 2 & $\underline{\mathrm{s}} \cdot \chi \underline{\mathrm{f}}$ \\
\hline 9 & fqqs & 'irritate’ & 2 & $\underline{\text { fq.qs }}$ \\
\hline 10 & $\mathrm{ft} \chi$ & 'roll' & 2 & $\underline{f} . t \underline{\chi}$ \\
\hline 11 & $\mathrm{t}-\mathrm{ftH}$ & 'she had an operation' & 2 & tff.t $\underline{\mathrm{H}}$ \\
\hline 12 & $\mathrm{t}-\mathrm{k} \int \mathrm{f}$ & 'it dried’' & 2 & tk․ $\int \underline{f}$ \\
\hline 13 & $t-\int t f-t$ & 'you crushed' & 2 & $t \underline{t} . t \underline{t} \mathrm{t}$ \\
\hline 14 & $\mathrm{t}-\mathrm{kks}-\mathrm{t}$ & 'you took off' & 2 & th.kst \\
\hline 15 & $t-\chi t^{\mathrm{S}} f-t$ & 'you stole' & 2 & $\mathrm{t} \underline{\chi} \cdot t \underline{\mathrm{tft}}$ \\
\hline 16 & $t-f s \chi-t$ & 'you cancelled' & 2 & $\mathrm{t} \underline{f} . \mathrm{s} \underline{\chi} \mathrm{t}$ \\
\hline 17 & t-qssf & 'it shrunk’ & 2 & tqus.s $\underline{f}$ \\
\hline 18 & $s-f q q s=t$ & ‘irritate him’ & 2 & sf́q.qst \\
\hline 19 & $\mathrm{t}-\mathrm{fk}-\mathrm{t}=\mathrm{stt}$ & 'you gave it (FEM)' & 3 & tflk.tsttt \\
\hline 20 & t-ss-kff-t & 'you dried' & 3 & ts. sk. $\int \underline{f t}$ \\
\hline 21 & $\mathrm{t}-\mathrm{kks}-\mathrm{t}=\mathrm{stt}$ & 'you took it off (FEM)' & 3 & tk.ks. \\
\hline 22 & $\mathrm{t}-\mathrm{ftk}-\mathrm{t}=\mathrm{stt}$ & 'you sprained it (FEM)' & 3 & te.te.t.tstt \\
\hline 23 & $\mathrm{t}-\mathrm{ft} \chi-\mathrm{t}=\mathrm{stt}$ & ‘you rolled it (FEM)’ & 3 & tf.$t \underline{\chi} \cdot$ ts $\underline{t t}$ \\
\hline 24 & $t-s s-k \int f-t=s t t$ & 'you dried it (FEM)' & 4 & ts .s $\underline{k} . \int \underline{f} . t \underline{t s t}$ \\
\hline
\end{tabular}

\section{Table I}

The linguistic material analysed in the acoustic experiment.

Syllabification of each form on the basis of the author's native speaker intuitions is indicated. These judgements are in accordance with the parsings provided by Dell \& Elmedlaoui, except for forms with initial and final geminates, which are indicated by a question mark.

beginning. The utterances were recorded with a Sony ECM-MS957 microphone, and the recorded signals were imported from Marantz PMD670 solid state recorder to SoundForge at a sampling rate of $16,100 \mathrm{~Hz}$. All subsequent waveform and spectrogram editing was then performed using Praat (Boersma 2001). The complete dataset consisted of 2304 stimuli: 864 of which were underlyingly voiceless $(24$ forms $\times 6$ repetitions $\times 6$ subjects), and 1440 were filler items ( 40 forms $\times 6$ repetitions $\times 6$ subjects).

Results. Table III gives the number of repetitions produced with or without a voiced vocoid for each speaker. Results show that over $88 \%$ of the 864 utterances were produced with no voiced schwa (766 out of 864 utterances). Illustrations of such productions are given in Figs 5-7 (see 


\begin{tabular}{|c|c|c|c|}
\hline speaker & dialect & age & in France for \\
\hline $\begin{array}{l}\text { M1 } \\
\text { M2 }\end{array}$ & Agadir & $\begin{array}{l}31 \\
26\end{array}$ & $\begin{array}{c}1 \text { year } \\
2 \text { years }\end{array}$ \\
\hline $\begin{array}{l}\text { M3 } \\
\text { F1 }\end{array}$ & Anti-Atlas & $\begin{array}{l}49 \\
26\end{array}$ & $\begin{array}{c}15 \text { years } \\
2 \text { years }\end{array}$ \\
\hline $\begin{array}{l}\text { M4 } \\
\text { F2 }\end{array}$ & High Atlas & $\begin{array}{l}49 \\
26\end{array}$ & $\begin{array}{c}15 \text { years } \\
2 \text { years }\end{array}$ \\
\hline
\end{tabular}

Table II

List of speakers who participated in acoustic data collection.

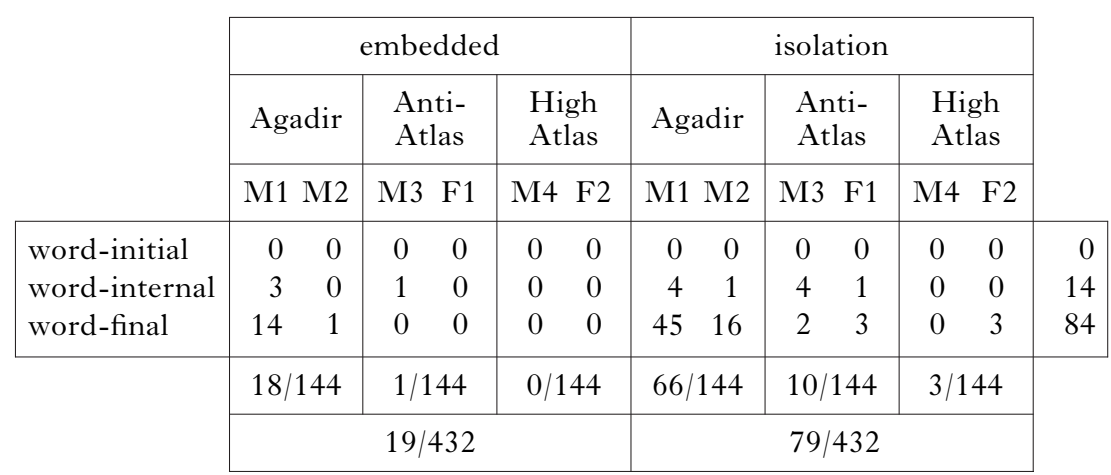

Table III

Number of tokens produced with a voiced schwa in word-initial, wordinternal and word-final positions for each subject in two different contexts (embedded and isolation). Dialectal information for each speaker is provided.

also Fig. 4). Only 11 repetitions contained schwas in the pronunciation of Anti-Atlas subsystem subjects (M3 and F1), and even fewer in the High Atlas productions ( 3 repetitions, all by F2). By contrast, voiced schwas were widely attested in the realisations of Agadir speakers. Indeed, $89 \cdot 36 \%$ of the forms produced with a schwa were realised by the Agadir speakers.

Consider next the question of the distribution of the repetitions. Of the 98 repetitions produced with a voiced schwa, 84 were produced in wordfinal position (only 14 in internal position and none initially). ${ }^{14}$ As already

14 This is an important difference between Tashlhiyt and the other Berber dialects where schwa epenthesis has been reported (e.g. Tarifit and Taqbaylit Berber). In these two dialects, schwa epenthesis is attested not only in internal position but also in word-initial position. 


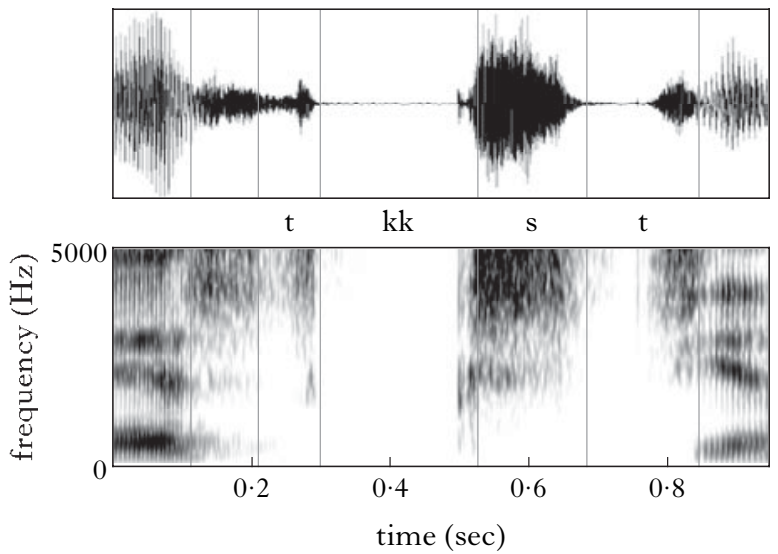

Figure 5

Waveform and spectrogram of [tkkst] 'you took off', as realised by M3, taken from the carrier sentence innajas _ jat twalt. This figure shows the absence of a voiced schwa within the underlyingly vowelless word.

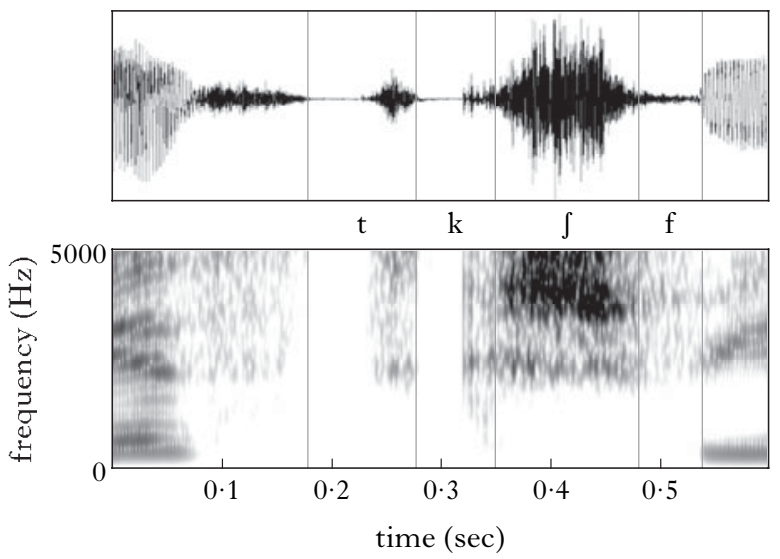

Figure 6

Waveforms and spectrograms of [tkff] 'it dried', as realised by $\mathrm{F} 1$, taken from the carrier sentence innajas jat twalt. This figure also shows the absence of a voiced schwa vowel within the underlyingly vowelless word.

noted, the presence of a voiced schwa following the final consonant of a word was also reported by Coleman (2001). Contrary to his view, however, there appears to be no direct relationship between the voiced vocoids observed and the syllable structure of Tashlhiyt. Though in some shorter forms (e.g. [ksə]), final schwa may occur adjacent to a syllabic consonant - and one might claim that this schwa is a nucleus of an open syllable - in longer forms this vocoid systematically appears after the final 


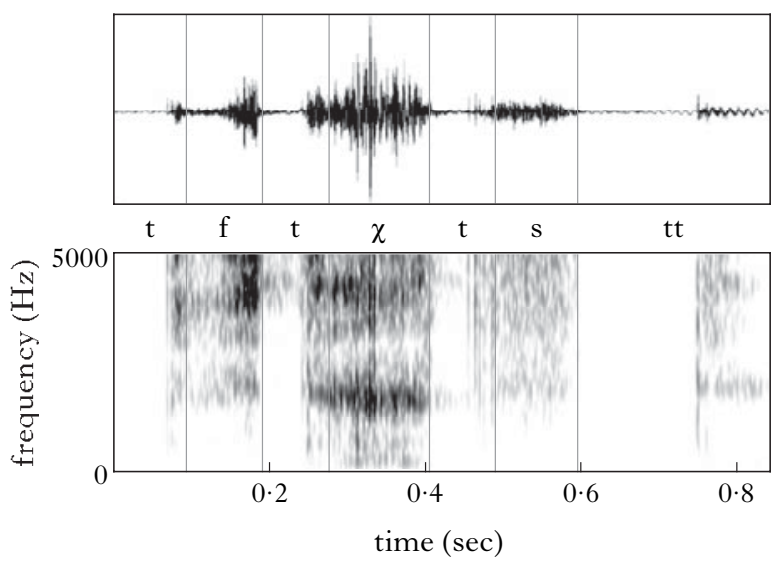

Figure 7

Waveform and spectrogram of [tft $\chi \mathrm{tstt}$ ' you rolled it (FEM)', as realised by $\mathrm{F} 2$, in isolation. This figure shows the absence of a voiced schwa within the underlyingly vowelless word (cf. note 18).

coda consonant. In [tfs $\chi$ tə], for example, it appears after the final stop but not adjacent to $\mid \mathrm{f} /$ and $|\chi|$, which are the syllabic consonants. At the level of phonological interpretation, these vocoids cannot be considered as realisations of phonological nuclei, unless a form like [tkkststtə] 'you took it off', as realised by M2, is considered to be monosyllabic, with a highly improbable onset of eight consonants. A more plausible interpretation of the presence of these vocoids may be related to prosodic constituents higher than the syllable. Several aspects suggest that phrasal boundaries are involved in the manifestation of this vocalic element, suggesting that vocoid insertion is one of the phonetic cues used to mark a phrase boundary, possibly in addition to other phonetic cues, such as final lengthening. First, it was mostly the forms produced in isolation which contained such final schwas (69 out of 84 word-final schwa productions). These forms were produced in isolation, so that the end of a word was also the end of the utterance. Second, closer examination of the productions of M1, the subject who produced most of these word-final schwas, revealed that he quite often inserted these vocoids even after the coda of the verb [in.na.jas] 'he told him', which is part of the carrier sentence (see Fig. 8). The realisation of this final vocoid is most probably related to the intonational break followed by a pause that this subject produces before uttering the voiceless words ${ }^{15}$ Insertion of a schwa in pre-pausal position is a well-attested characteristic of the pronunciations of some Agadir subsystem areas. The variety of Tarrast, a small town about five

15 M1's data show that 41 out of 72 repetitions were produced with such a pause. All of these productions were characterised by the presence of a voiced vocoid after the final /s/ of [innajas]. 


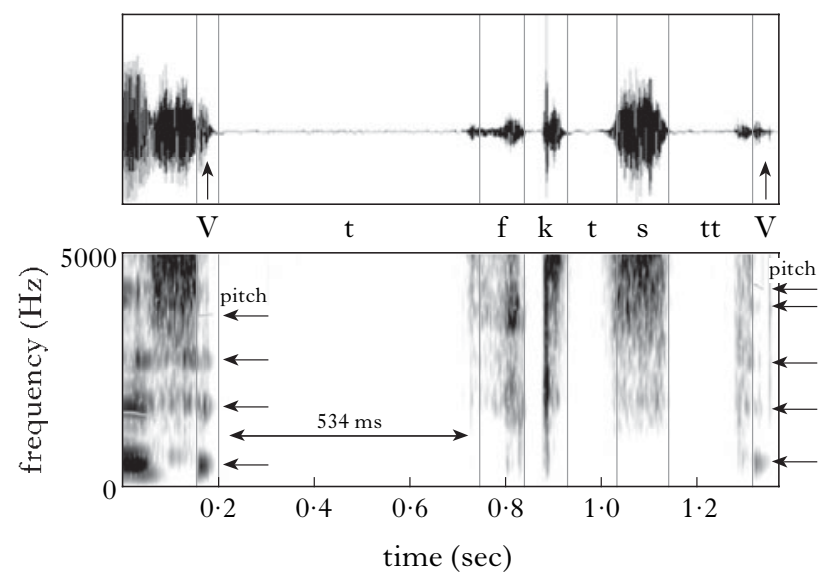

Figure 8

Waveform and spectrogram of the form [tftktstt] 'you sprained it (FEM)', as realised by M1, taken from the carrier sentence innajas _ jat twalt 'he told him _ once'. Arrows show the acoustic manifestations of two voiced schwas, labelled $\mathrm{V}$, produced in prepausal position.

kilometres from Agadir city, is a case in point: phrase-final schwa insertion is such a telltale sign of this dialect that speakers of other dialects humorously mimic Tarrast speakers by producing schwas in final position (speakers of the Tarrast variety typically insert phrase-final schwas when they speak Moroccan Arabic as well).

Another argument showing that these voiced vocoids cannot be interpreted as realisations of phonological nuclei is provided by the high variability of their distribution within one and the same form. In many cases, the same item may be produced with or without a schwa by the same subject. Some productions exhibit even higher variability. This is the case, for instance, of the forms / $t$-fs $\chi-t /$ 'you cancelled' and /s-fqqs=t/ 'irritate him' (test items 16 and 18 in Table I), as produced by speakers $\mathrm{M} 2$ and M1 respectively. The form /t-fs $\chi$ - $\mathrm{t} /$ is produced in three different ways by M2: with no schwa, [tfs $\chi \mathrm{t}$ ], with a word-internal schwa, [tfsə $\chi \mathrm{t}$ ], and with word-final schwa, [tfs $\chi \mathrm{t}$ ] . The form /s-fqqs=t/ is also produced in three different ways by M1 (i.e. [sfqqst], [sfqqstə] and [sfəqqst]). In none of these realisations do the schwas occur where Coleman would predict them to (i.e. [səfq.qəst]). Notice, moreover, that not all the forms realised by Agadir speakers contain schwas. They may realise long voiceless sequences with no voiced vocoid at all. Such is the case for the items [tkkst], [tfs $\chi \mathrm{t}]$, [tsskfftstt] and [tftktstt] (cf. Fig. 4).

As stated above, only 14 tokens were produced with word-internal schwas (i.e. $1.63 \%$ ). These tokens correspond to the repetitions of items 8, 10, 11, 13 (cf. Fig. 3), 16 and 18. The question here is to determine whether the schwas in these words, though extremely rare, can 
be explained as filling a syllable nucleus, as proposed by Coleman, or whether they have some other explanation. Clearly, these vocoids cannot be interpreted as mere transitions between segments, because if such vocoids are merely an aspect of the realisation of a voiced consonant, as Dell \& Elmedlaoui claim, there is no obvious reason for them to be voiced when they appear between voiceless segments. The presence of these schwas seems to be due to the influence of Moroccan Arabic, a national language with which Tashlhiyt and other Berber dialects have been in contact for centuries, and which resembles it in many respects (Boukous 1995, 2000). All of the six forms in question are Moroccan Arabic loanwords. ${ }^{16}$ The inserted schwas in these six words occur just where schwas occur in the Moroccan Arabic source words. Like Tashlhiyt, Moroccan Arabic has three full vowels /a i u/. Unlike Tashlhiyt, it has in addition a schwa, the location of which can, in some instances, be the only feature distinguishing otherwise similar words (compare [Həbs] 'prison (N)' and [Hbəs] 'imprison (vB)'). In Tashlhiyt, these loanwords are normally produced without schwa, but this is not the case for all native speakers. It is a fact, totally unsurprising from a sociolinguistic point of view, that native speakers of Tashlhiyt (especially those who grow up in Agadir or in other Arabic-speaking cities) tend to mimic the Moroccan Arabic pronunciation, which is considered more prestigious. Boukous (2000) illustrated this phenomenon by means of a sociolinguistic investigation of the degree of linguistic competence of 50 young Tashlhiyt native speakers, divided into two groups ( 20 people from the countryside and 30 belonging to the city). His results, illustrated by the production of consonant-only words, showed that, unlike country people, those belonging to the city inserted internal schwa vowels in these forms. According to Boukous (2000: 46): 'this articulatory habit is probably acquired through the use of Arabic dialect, where schwa insertion seems to correspond to a phonotactic necessity' [translation mine].

2.1.1.2 Fibrescopy. Vocal fold vibration is the usual source of sound in vowels. The fibrescopic experiment was conducted in order to provide direct evidence that underlying voiceless obstruent-only words are produced with no vocal fold vibration. The occurrence of a voiced schwa within a sequence of voiceless obstruents is easily observable on videofibrescopic data. Figure 9 gives a representation of one state of the glottis during the production of a voiceless obstruent sequence (Fig. 9a) and one state of the glottis during the production of the schwa vowel contained in [fsəð] 'cancel', a Moroccan Arabic item having a schwa before the final consonant (Fig. 9b). When looking at the abduction/adduction states of the vocal folds and the distance between the arytenoid cartilages, we observe clear differences between the voiced segment (with adducted vocal folds and arytenoid cartilages) and the voiceless segment (with an open glottis and separated arytenoid cartilages).

16 The insertion of internal schwa in Moroccan Arabic loanwords is not systematic, since the same item may be produced with no internal schwa by the same subject. 
(a)

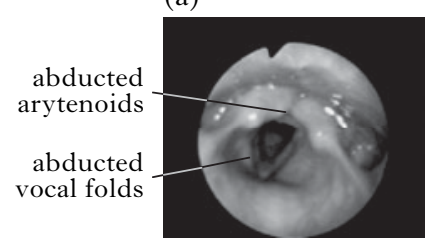

(b)

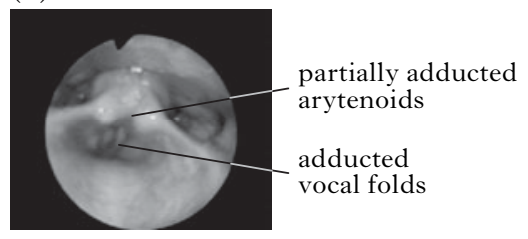

Figure 9

State of the glottis during the production of a voiceless sequence (a) and during the production of a voiced schwa (b).

Data and subjects. Two male native speakers served as subjects for this experiment: a 30-year-old (M7, the author) and a 26-year-old from High Atlas (M8). ${ }^{17}$ The video-endoscopic experiment was performed by means of a flexible nasofibroptic laryngoscope (Olympus ENF P3) with video recording (at 25 frames per second). A fibrescope was inserted through the nostril of the speaker. A camera (Sony XC-999 P) was fixed on the external side of the fibrescope, allowing recording on a video film on a Umatic Sony tape recorder (VO-5800 PS). The internal side was stabilised over the larynx, providing an immediate visualisation of the dynamic behaviour of the laryngeal region. The laryngeal evaluation included the abduction and adduction movements of the vocal folds, as well as inward and forward movements of the arytenoid cartilages. A synchronisation signal was recorded on one channel of the tape recorder for frame identification. The film was visualised for analysis on Adobe Premiere (for video sequences) and Adobe Photoshop (for picture analysis). The corpus consisted of the same forms as for the acoustic analysis (see Table I above). Other forms (composed of vowels and voiced consonants) were also included in the experiment. Each item was produced in isolation, 12 times by M7 (total $=288)$, and 5 times by M8 (total $=120)$. There were thus 408 utterances in total. The interval between consecutive items was approximately $2-3$ seconds.

Results. Observation of the productions of M7 and M8 shows that they behave in almost the same way. The 288 realisations of M7 show a clear opening of the glottis from the onset to the offset of the 24 items. Only one repetition out of the 120 recorded by $\mathrm{M} 8$, the form $/ \mathrm{t}-\mathrm{ftH} /$ 'she had an operation', was produced with complete glottal adduction. This closing gesture was observed word-finally. In this position, M8 produced a schwa comparable to the ones observed in the Agadir subjects' realisations in the acoustic experiment (i.e. [tfthə]). All the remaining 119 forms show an uninterrupted opened glottis through the sequences, with clear abducted

17 Fibrescopy is a highly invasive method of investigation. It is therefore hard to get enough volunteers for such studies. This explains why the author is one of the two participants. Only Tashlhiyt data from the other participant are presented for illustration. The author's productions are referred to to highlight the level of agreement between the two subjects. Video files of selected items are available (August 2008) at http://lpp.univ-paris3.fr/equipe/rachid_ridouane/video.doc. 

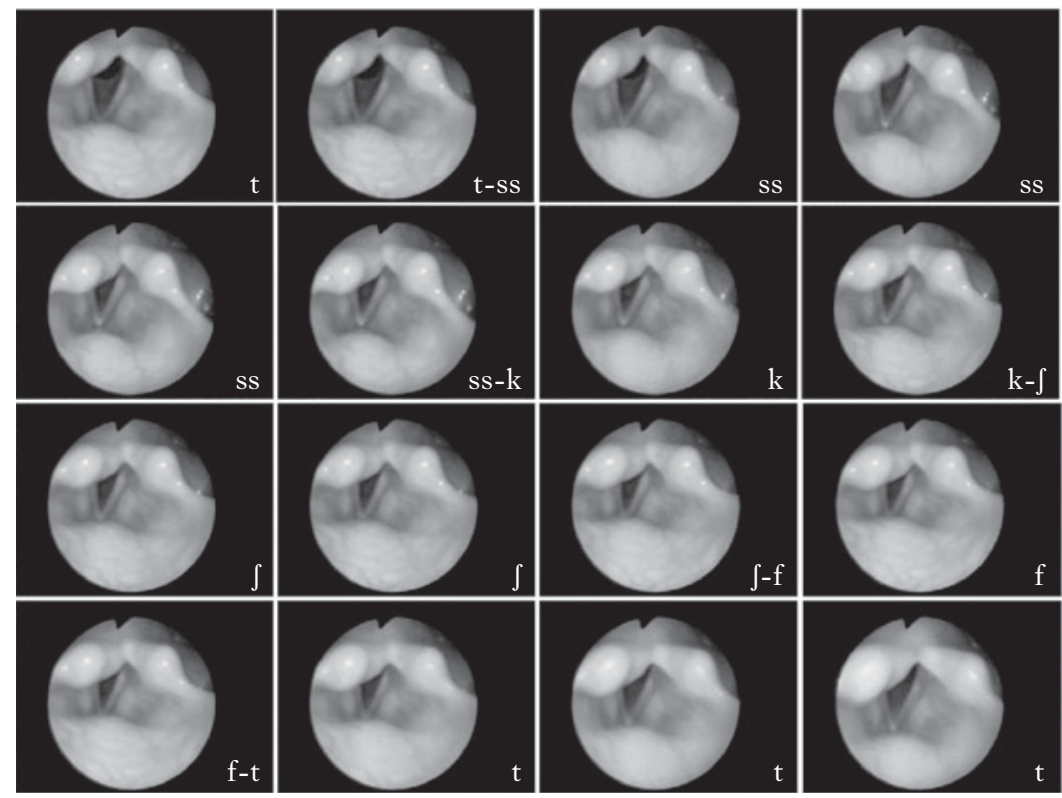

Figure 10

States of the glottis during the production of [tsskfft] 'you dried' by M8, showing total abduction of the vocal folds and the arytenoids.

vocal folds. During the production of these words, the vocal folds are never in vibration. Figures illustrating this continuous abduction state of the glottis during some voiceless words are shown below.

In Fig. 10, for the form [tsskfft] 'you dried', the first frame, corresponding to the acoustic onset of $/ \mathrm{t}$ / (approximately one frame before the image corresponding to the acoustic oral release), shows that the glottis is wide open: both the vocal folds and the arytenoid cartilages are abducted. As is clearly visible from Fig. 10, the glottis maintains this clear opening throughout the whole word.

This configuration of the glottis is virtually the same for all the productions of the 24 sequences of voiceless obstruents analysed, regardless of the number of consonants they have. A sequence containing up to 8 voiceless obstruents, as in [tft $\chi \mathrm{tstt}$ ' 'you rolled it' (Fig. 11), for example, is also produced with the glottis wide open from the onset of the word-initial $\mid t /$ to the release of the final geminate $/ \mathrm{tt} /$.

As indicated previously, some Tashlhiyt items have been borrowed from Moroccan Arabic. $/ \mathrm{s} \chi \mathrm{f} /$ 'fade away' is one such item. In the Moroccan Arabic pronunciation, an epenthetic schwa is produced before the last consonant ([s $\chi \partial f])$, and an adduction gesture is necessary for the realisation of this vowel. This adduction gesture is clearly visible on the fibrescopic images displayed in Fig. 12 (from data recorded by M7). Observation of this realisation shows that the closing gesture of the glottis 


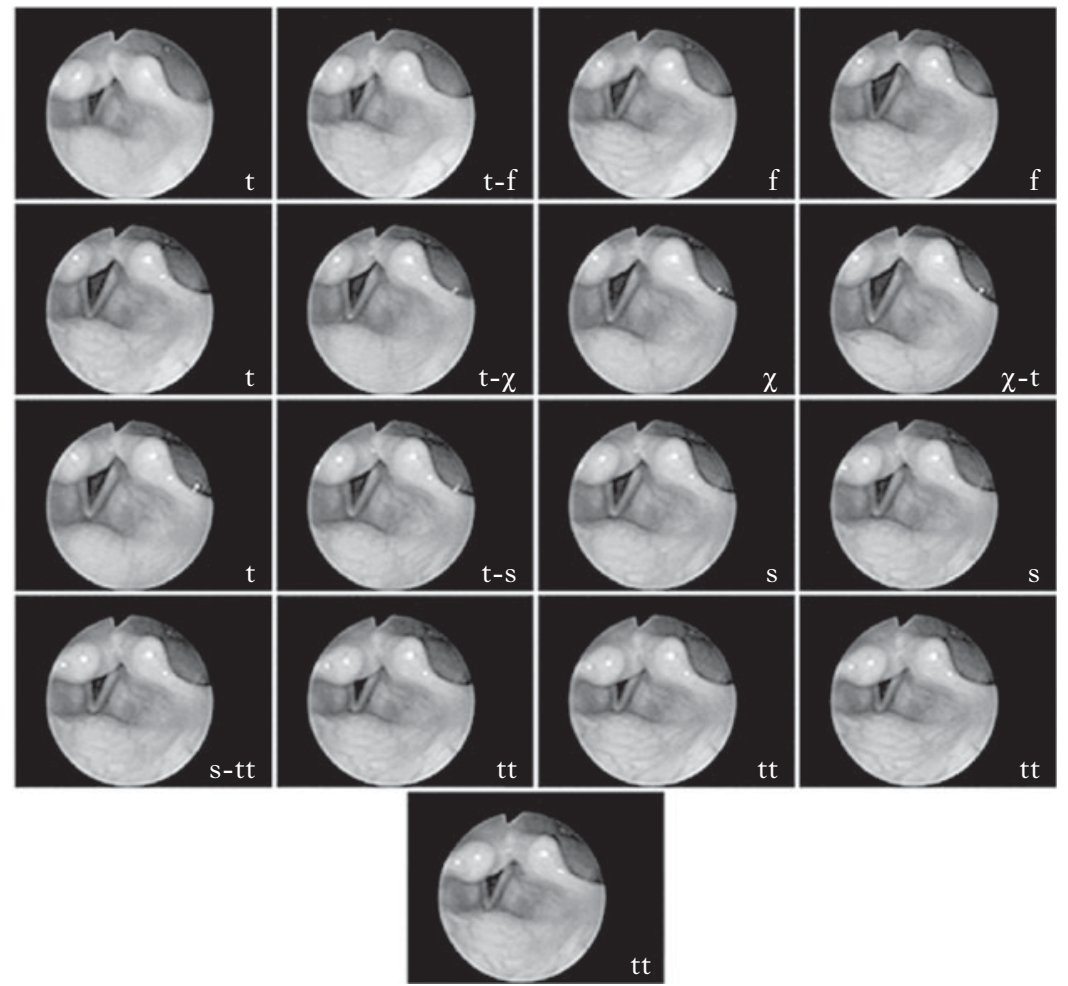

Figure 11

States of the glottis during the production of [tft $\chi \mathrm{tstt}$ ] 'you rolled it (FEM)' by M8, showing total abduction of the vocal folds and the arytenoids.

is initiated during the preceding uvular fricative to reach complete glottal closure during the vowel, and then an opening gesture is initiated for the production of the following voiceless fricative. This configuration of the glottis is quite different from that observed during the Tashlhiyt pronunciation of this loanword. As is shown in Fig. 13, this item as realised by M8 displays no such glottal closing either in the vicinity of the syllabic consonant $/ \mathrm{f} /$ or elsewhere in the utterance.

2.1.2 The 'devoiced-schwa' realisation. The phonetic data presented so far provide compelling evidence that voiced schwa is not a segment at the level of phonetic representation in Tashlhiyt. The analysis of the acoustic data explains why some researchers have found sporadic examples of vowels in what have been reported to be vowelless words by other researchers. The presence of this vowel in the final position of some subjects' utterances is interpreted as a cue to phrasal boundaries. Its presence in the internal position of some items is most probably due to the influence of Moroccan Arabic, a national language which has greater 

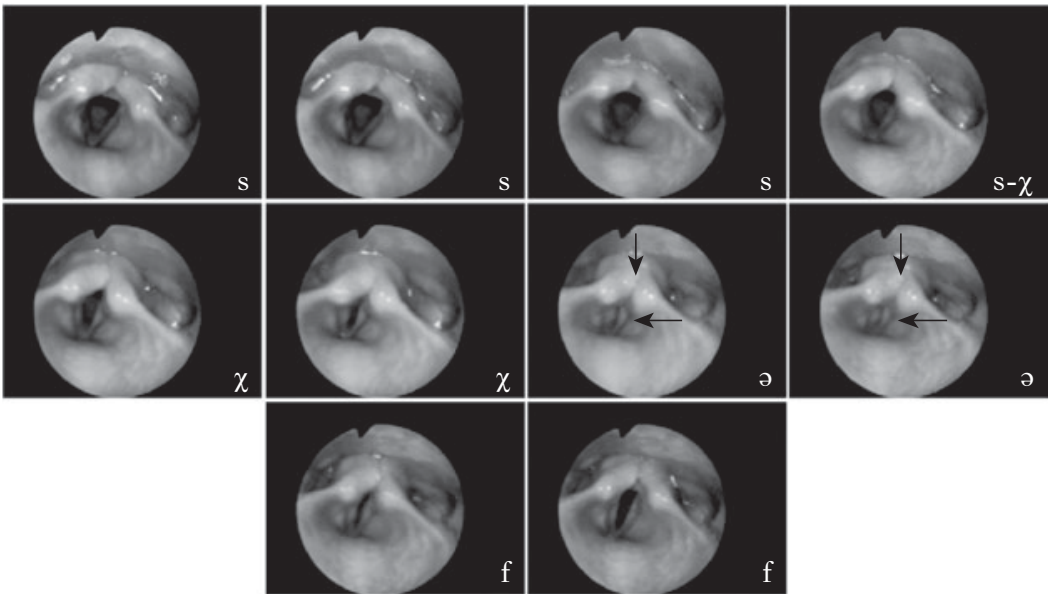

Figure 12

States of the glottis during the production of the Moroccan Arabic item [s $\chi$ əf] 'fade away' by M7. Arrows show the adduction of the vocal folds and the partially adducted arytenoids during the schwa.
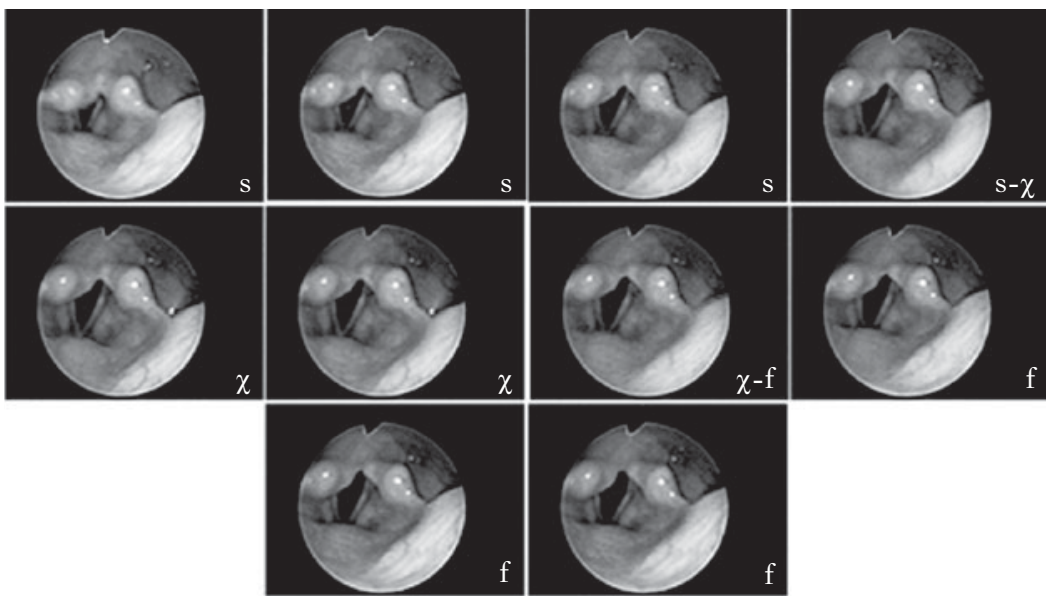

Figure 13

States of the glottis during the production of the Tashlhiyt item [s $\mathrm{f}$ ] 'fade away' by M8, showing total abduction of the vocal folds and the arytenoids.

prestige than Tashlhiyt. The fibrescopic data provided additional evidence that the underlyingly vowelless words were quasi-systematically produced with an uninterrupted devoicing gesture from the onset to the end of each sequence. These findings provide important arguments in favour of Dell \& Elmedlaoui's account. Notice, however, that they do not 


\section{Rachid Ridouane}

totally rule out Coleman's schwa-nucleus theory: a voiceless word is not necessarily vowelless. Indeed, a proponent of Coleman's theory might argue that schwas in voiceless consonant contexts may coarticulate with their surrounding environment and become 'devoiced', hence the absence of voiced segments and the large opening of the glottis. In Japanese, where vowel devoicing has been more extensively examined, clusters containing devoiced vowels are produced with a large glottal opening (Sawashima 1971, Yoshioka 1981, Tsuchida 1997). The presence or absence of such schwas is discussed in this section. Vowel devoicing is a common phenomenon, which has been reported to occur in Japanese and in many other languages (e.g. Korean, English, French and Turkish). I show in this section that, unlike what has been reported for Japanese, Tashlhiyt voiceless clusters lack devoiced schwas. The main argument is drawn from a photoelectroglottographic (PGG) examination of the nature of laryngeal/supralaryngeal adjustments produced during the realisation of voiceless words. The aim is to determine whether, as in Japanese, these adjustments provide evidence for the presence of devoiced vocalic gestures within voiceless obstruent clusters.

Before presenting the results of this study, it is useful to consider more closely the implications of the claim that Tashlhiyt voiceless syllables may contain devoiced schwas. If this claim is correct, it would imply that all the schwas inserted by the phonological component in underlyingly voiceless words would be systematically subject to devoicing, since these words, which may contain two or more syllables, are quasi-systematically produced with no vocal fold vibration. In other words, a three-syllable word of the type [tf.t $\chi$.tstt] would surface with three devoiced schwa vowels (i.e. [təof.tə̊ $\chi$.tə̊stt]). This is highly improbable, and rather unusual from a cross-linguistic point of view. In Japanese, the process of vowel devoicing may result in a shortened, partially voiced vowel. Its frequency depends on many factors, e.g. the type of dialect (more devoicing in Tokyo than in Osaka), the nature of the obstruents surrounding the vowel (higher frequency of devoicing when surrounded by stops or affricates than by fricatives), the type of speech (more devoicing in spontaneous speech compared to careful speech), etc. The systematic devoicing of two, three or more vowels within a single word is also highly unusual. According to Tsuchida (2001), there is a prohibition against having devoiced vowels in two consecutive syllables in Japanese (see also Kondo 2005). The form [sekifitsu] 'room made of rock', for example, contains two consecutive devoiceable high front vowels, but only the first or the second vowel in the sequence is devoiced, never both. Another important difference from Japanese is related to the type of vowels devoiced. In Japanese, only high vowels tend to devoice, while other vowels quasi-systematically maintain their voicing even when surrounded by voiceless consonants. ${ }^{18}$ According

18 The greater tendency of high vowels to devoice than comparable lower vowels has been documented for many other languages (see Greenberg 1969). In a study on the height effects on vowel devoicing in Korean, Mo (2007) reported that only two tokens out of 573 non-high vowels (including /a/) were devoiced. 


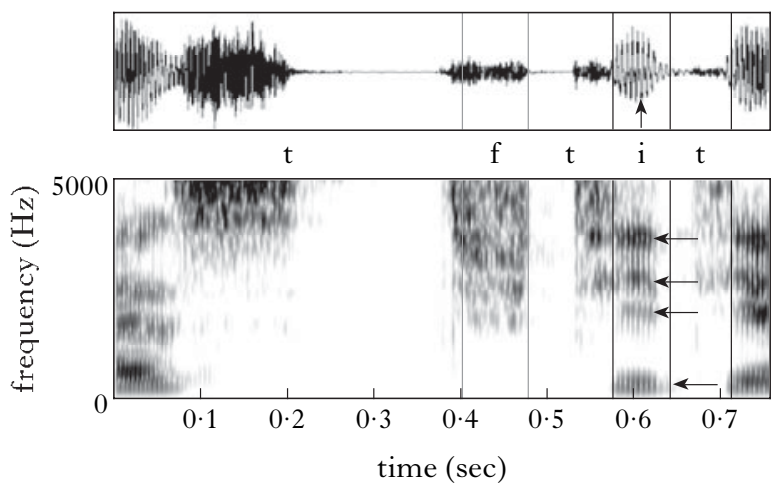

Figure 14

Waveform and spectrogram of the form [tftit] 'you went', as realised by $\mathrm{M} 4$, taken from the carrier sentence innajas jat twalt 'he told him _ once'. Arrows mark characteristics of a voiced high vowel: periodic wave, formant structure and voicing bar.

to Ohala (1997), the reason for this is that high vowels, like obstruents, are produced with close constriction, which may impede the airflow necessary for the vibration of the vocal folds. If Tashlhiyt schwas are systematically devoiced in the context of voiceless consonants, one might also expect the devoicing to affect high vowels in the same context. To test this, 12 items, each containing one high vowel $(/ \mathrm{i} /$ or $/ \mathrm{u} /)$ surrounded by several voiceless obstruents, were recorded by the six native speakers who participated in the acoustic experiment presented above. The items analysed are presented in App. 1. Each item was produced six times by each subject (three times in isolation and three times in a carrier sentence). Examination of the waveforms and spectrograms shows that all of the 432 items were produced with visibly voiced high vowels. ${ }^{19}$ As illustrated in Fig. 14 (see also Fig. 1 above), vowels in these contexts show clearly visible acoustic manifestations of a vowel (i.e. a period of time displaying periodic wave, voicing and formant structure). If we postulate the presence of devoiced schwas in the underlyingly voiceless words, we must then explain why high vowels $/ \mathrm{i} \mathrm{u} /$, which are more likely to undergo devoicing, are never devoiced by the six subjects, while they systematically devoice schwa.

Let us suppose, for the sake of discussion, that in Tashlhiyt only the alleged epenthetic schwas are subject to systematic devoicing.

19 There are various factors which might explain why the six subjects systematically maintain the voicing of the high vowels in these words. The first may be related to the type of speech in such laboratory experiments (more careful and probably more hyperarticulated than it would be in spontaneous speech). The second may be related to the necessity of maintaining the voicing of this vowel to convey F0-based prosodic information. This, in turn, raises the question of how pitch events are aligned in relation to obstruent nuclei in voiceless words. To the best of my knowledge, this aspect has not yet been investigated. Further work is needed to determine how stress is marked during the production of such words. 


\section{Rachid Ridouane}

Acoustically, a vowel is traditionally claimed to be devoiced if voicing ceases during the vowel while some aperiodic energy continues to be apparent in the spectrogram. Ideally, this aperiodic energy would display formant transitions indicating an open, vowel-like vocal tract. In many cases reported in literature, however, a devoiced vowel does not exhibit characteristic vocal tract resonances. Instead, it is realised as a period of aspiration or frication noise following obstruent release, resulting in a non-distinct segment boundary between the devoiced vowel and an adjacent voiceless obstruent. This makes the exact delimitation of such vowels within voiceless obstruent clusters rather hard to obtain on the basis of visual inspections of waveforms and spectrograms. ${ }^{20}$ In Japanese, for example, when waveforms and wideband spectrograms of devoiced vowels are examined, no visible characteristics of vowels are found (see Mo 2007 for the same observation on devoiced vowels in Korean). Tsuchida (1997), for instance, compared the waveforms and spectrograms of the Japanese word suki 'ski' (where /u/ is devoiced) and the English word $s k i$, and found that the two were virtually indistinguishable. The absence of any obvious acoustic characteristics of vowels in these clusters has led some researchers to argue that they are not devoiced, but deleted (e.g. Jun \& Beckman 1993, cited in Tsuchida 1997).

Though acoustically, the presence of a devoiced vowel may be hard to identify, at the articulatory level, specific laryngeal adjustments are claimed to be involved in the production of a voiceless cluster containing such vowels. These configurations show specific glottal movements signalling the presence of a devoiced vocalic target. This has been demonstrated for Japanese in numerous studies (Sawashima 1971, Yoshioka 1981, Tsuchida 1997, Fujimoto et al. 2002). Specifically, when a devoiced high vowel occurs between two voiceless stops (or between a stop and a fricative), a monomodal glottal opening pattern is observed, with the maximal glottal width often reached during the production of the devoiced vowel. The reason for this is that devoiced vowels are produced with larger glottal opening than unaspirated voiceless stops. When a devoiced vowel occurs between two voiceless fricatives, the glottis is wide open in each of the fricatives, but is almost closed during the vowel, resulting in a bimodal pattern. This configuration is probably due to the fact that vowels are less likely to devoice when they occur between two voiceless fricatives (Yoshioka 1981, Tsuchida 1997). These glottal configurations are quite different from the patterns observed during the production of voiceless consonant clusters not containing devoiced vowels, as in some Swedish, German, Icelandic and English voiceless clusters. Results from Löfqvist

${ }^{20}$ No acoustic characteristics of vowels were found within stop-stop clusters in Tashlhiyt, excluding the presence of devoiced vowels in this context (cf. Figs 1, 3, 4 and 5). In clusters including fricatives (mainly uvulars and aryepiglottals), however, it is hard to determine whether the aperiodic energy is due to a devoiced vowel or to the fricative. This is, for example, the case in the form [tft $\chi \mathrm{tstt}]$ illustrated in Fig. 7, where the uvular fricative displays an [h]-like formant structure (see also Figs 3 and 5). 
\& Yoshioka (1980) for Swedish and Yoshioka et al. (1981) for English show that the laryngeal adjustments produced are closely related to the manner of articulation of the voiceless obstruents in the cluster and the way they are combined. According to Löfqvist \& Yoshioka (1980), these laryngeal and oral articulatory movements are tightly co-ordinated, in order to meet the aerodynamic requirements of speech production: each voiceless obstruent accompanied by frication noise (or aspiration in languages where it is phonologically distinctive) tends to require a specific separate peak glottal opening. In the remaining of this section I present the main results of Ridouane et al. (2007)'s PGG examination of Tashlhiyt voiceless words and sentences. This study was mainly descriptive, and aimed at demonstrating the intimate linking between laryngeal and supralaryngeal gestures in completely voiceless utterances (including clusters of up to 18 adjacent voiceless obstruents). These results are relevant for the question under discussion in this section. To provide a comparison with what is known about the laryngeal configuration during Japanese clusters containing devoiced vowels and Germanic voiceless obstruent-only clusters, the aim is to determine whether the laryngeal and supralaryngeal adjustments produced during Tashlhiyt voiceless words provide any evidence for the presence of a voiceless vocalic target.

\subsubsection{Photoelectroglottography.}

Data and subjects. Two male native speakers, M7 (the author) and M9 (a 34-year-old native speaker from Ddchaira, a locality 10 kilometres from Agadir) participated in the experiment. ${ }^{21}$ The speech material consisted of 14 voiceless words, embedded in a carrier sentence ini jat twalt 'say _once', and three voiceless sentences. ${ }^{22} \mathrm{~A}$ sample of the data is presented in Fig. 15. The top panel shows the acoustic waveform of [t $\mathrm{t} t \mathrm{ft}]$ 'you crushed'. The second panel shows the glottographic pattern, which indicates the duration, degree and number of glottal opening peaks. The vertical axis shows the amount of light passing through the glottis (the units are arbitrary). The third panel indicates the velocity of glottal opening and closing gestures (i.e. the derivative of the transillumination data). The number of glottal opening peaks in voiceless words was calculated algorithmically as the number of (negative) zero crossings in the velocity signal. The number of peaks was averaged over the repetitions of each form for each speaker (voiceless sentences were not averaged) ${ }^{23}$

Results. Though some amount of variability is observed both within and between the two subjects, a general tendency clearly emerges: the number and the location of peak glottal openings are mainly related to the manner

21 As for the fibrescopic experiment, all the illustrations presented here are drawn from the productions of M9. See Ridouane et al. (2007) for illustrations drawn from M7.

22 Eight of the 14 voiceless words are presented in Table I (items 3, 7, 13, 19, 20, 21, $23,24)$. The remaining words and the three voiceless sentences are presented in Appendix B.

23 See Ridouane et al. (2006) and Ridouane et al. (2007) for a more detailed presentation of the method used. 
(a)

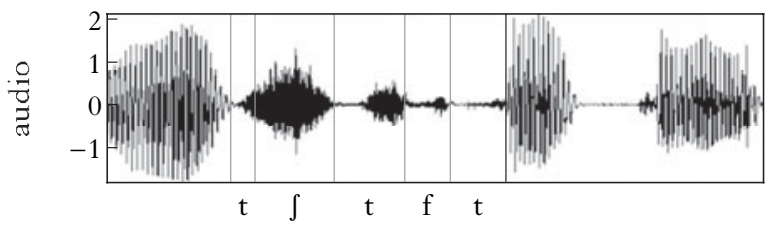

(b)

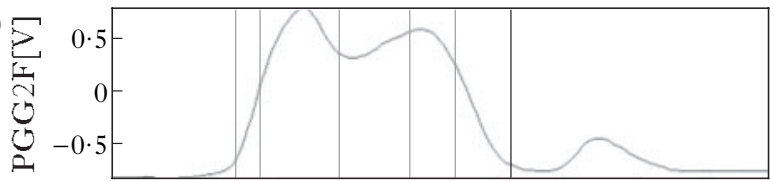

(c)

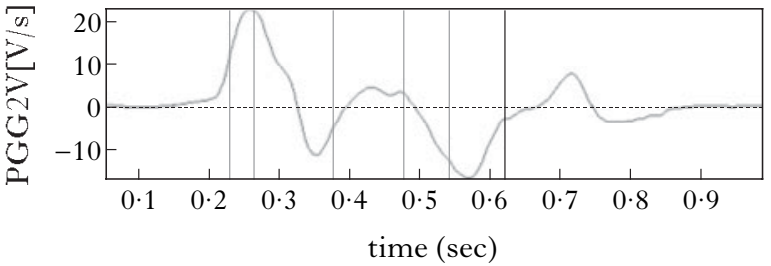

Figure 15

Illustration of adduction and abduction pattern in one repetition of [t $\left.\int \mathrm{tft}\right]$ 'you crushed'. (a) audio; (b) glottographic pattern; (c) velocity signal (details in the text).

of articulation of the obstruents present in the sequence and the way they are combined. Contrary to what has been observed in Japanese, glottal opening in Tashlhiyt voiceless words displays smooth transitions from the target of one obstruent to the next, without any deviation towards an alleged vocalic target. The following generalisation accounts for most of the data examined: a sequence containing $n$ non-adjacent voiceless fricatives is most often produced with $n$ peak glottal openings. These glottal openings are located during these fricatives.

The form [tk.ks.tstt], for example, contains three syllables. If each syllable contained a devoiced vowel, we would expect to observe three glottal opening peaks, the first being located during the word-initial stop-stop cluster. As shown in Fig. 16, this is not the case. This item is always produced with only two glottal opening peaks. The location of these laryngeal peaks follows that of the two fricatives. No specific laryngeal peak is observed in the first syllable, the voiceless stops being produced within the opening phase of the glottal gesture for the following fricative.

The importance of the manner of articulation of the obstruents present in a sequence in determining both the number and location of peak glottal opening becomes evident when one compares the two items [kst] and [t.ks] (Fig. 17). These two forms are different in the number of syllables they contain (one and two respectively). As shown in Fig. 17, both items, each composed of only one fricative, are quasi-systematically produced with one peak glottal opening. The location of this glottal peak also follows that of the fricative. These results can be combined with those presented in 


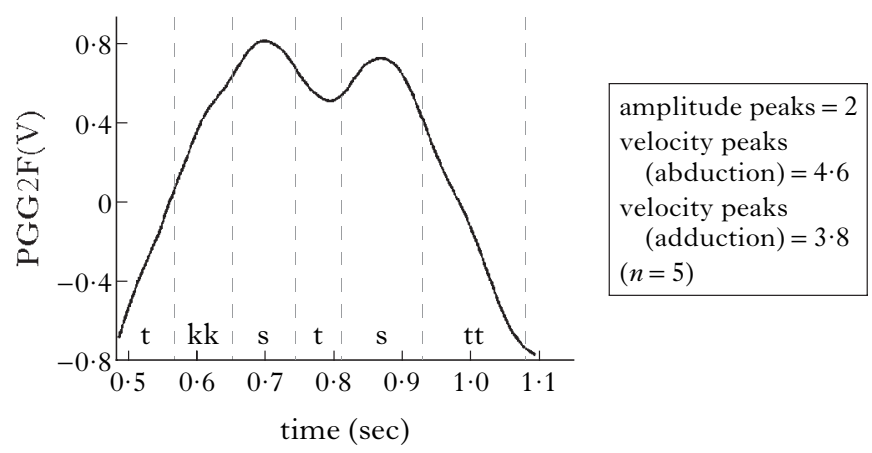

Figure 16

Averaged glottal abduction pattern for the form [tkkststt] 'you took it off', as realised by M9. The figure displays the number of amplitude peaks as well as the number of abduction and adduction velocity peaks. The number of repetitions of the sequence is indicated between parentheses.

The dashed lines delimit the onset and offset of each segment.

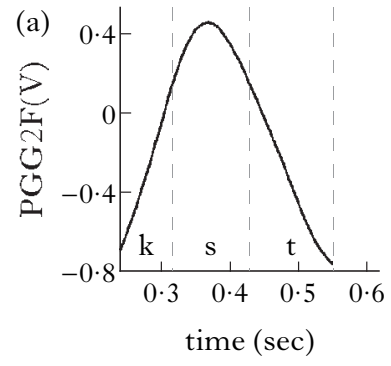

amplitude peaks $=1$

velocity peaks $($ abduction $)=1 \cdot 6$

velocity peaks (adduction) $=2 \cdot 2$

$(n=5)$ (b)

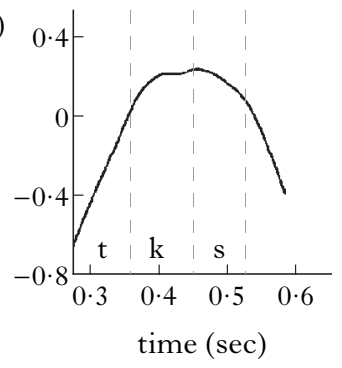

amplitude peaks $=1 \cdot 33$

velocity peaks (abduction) $=2 \cdot 66$

velocity peaks (adduction) $=1 \cdot 66$

$(n=3)$

Figure 17

Averaged glottal abduction patterns for (a) [kst] and (b) [tks], as realised by M9.

Ridouane et al. (2006), based on the analysis of [sk] clusters at word edges (e.g. [sk\#], [\#sk], [s\#k], [ks\#], [\#ks], [k\#s], [ssk\#sks], etc.). They also show that the modulation of glottal opening is mainly related to the manner of articulation of the obstruents present in the sequence. The twoconsonant clusters exhibit a single-peak pattern regardless of the placement of word boundaries. The peak almost always occurs during the fricative. The cluster [ssk\#sks] is often produced with three opening peaks located during the three fricatives. These results are also in general agreement with what has been reported for voiceless obstruent clusters in some Germanic languages, which show that glottal apertures observed 


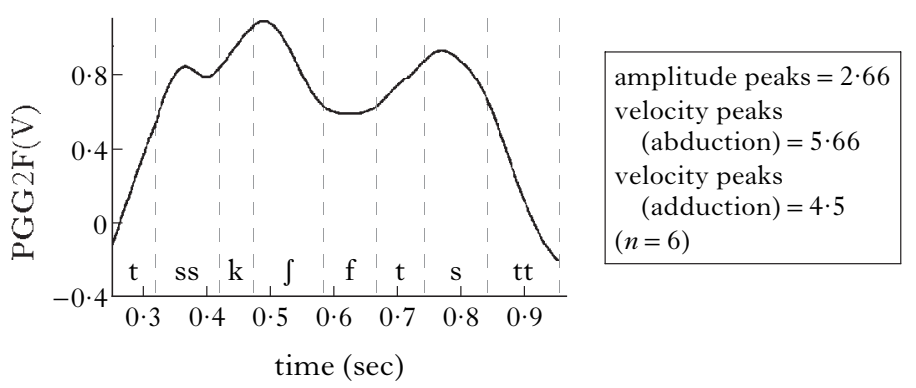

Figure 18

Averaged glottal abduction pattern for the form [tsskfftstt] 'you dried it (FEM)', as realised by M9.

display smooth transitions from the target of one obstruent to the next without any deviation towards a vocalic target.

Recall that, when a devoiced vowel occurs between two voiceless fricatives in Japanese, a bimodal pattern is often produced, with the two glottal opening peaks located during the two fricatives. This laryngeal configuration provides evidence that the two fricatives are not adjacent. In Tashlhiyt, two adjacent fricatives (even in cases where the second fricative is syllabic) are often produced with only one peak glottal opening, located during the leftmost fricative. This is the case for the form [ts.sk. example, which is produced with only three opening peaks. As shown in Fig. 18, the syllabic $/ \mathrm{f} /$ is produced within the closing phase of the glottal gesture for the preceding fricative, and within the opening phase for the following /s/ segment. This configuration provides additional evidence for the view that the obstruents present in this sequence are adjacent at the surface, and not separated by a devoiced schwa.

Interestingly, the general pattern observed in voiceless words also accounts for the laryngeal-supralaryngeal adjustments observed in voiceless sentences. Consider [tsskfftstt tft $\chi \mathrm{tstt}$ ], for example, which is illustrated in Fig. 19. This sentence, which contains six non-adjacent fricatives, is produced with six glottal opening peaks, located during these fricatives. The laryngeal configuration displayed in this figure shows that the changes in glottal opening are clearly related to the individual obstruents in the sequence, displaying smooth transitions from the target of one obstruent to the next, without any deviation to a voiceless vocalic target.

\subsection{Phonological data}

Acoustic, fibrescopic and photoelectroglottographic data provide compelling evidence that schwa, whether voiced or devoiced, is not a segment at the level of phonetic representation in Tashlhiyt. The only way of accommodating these findings with Coleman's schwa-nucleus theory is to claim that at the phonetic level, schwa vowels in voiceless consonant clusters are systematically 'hidden' or overlapped. In other words, the 

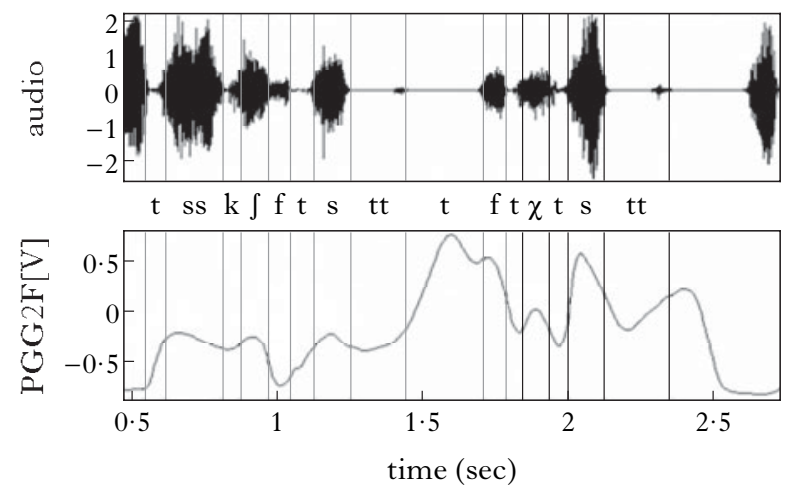

Figure 19

Waveform and glottal abduction pattern for [tsskfftstt tft $\chi \mathrm{tstt}$ ] 'you dried it and rolled it', as realised by M9, showing the six glottal peaks located during the six non-adjacent fricatives (velocity signal ignored).

distribution of schwas would be accounted for jointly by the phonological component, which would insert them to repair illegal structures, and by phonetic implementation, which would systematically mask them when occurring in voiceless clusters. I show in this section that this position is not tenable. To be syllabic, a schwa must correspond to a segment which can be independently manipulated by phonological grammar and which the syllable structure can refer to. Two arguments are provided below as evidence that such vowels are not present at the level of phonological representations. The first argument, based on versification, shows that voiceless obstruent-only syllables of the type [tk] are treated in Tashlhiyt poetry as light syllables, in which the second consonant is a nucleus and not a coda. The second argument, based on the behaviour of dental stops $v i s$-à-vis the process of assibilation, provides direct evidence that two consonants not separated at the underlying level by one of the full vowel / $\mathrm{a} \mathrm{i} \mathrm{u/are} \mathrm{adjacent} \mathrm{at} \mathrm{the} \mathrm{surface.}$

2.2.1 Versification. According to the schwa-nucleus theory defended by Coleman, a consonant sequence of the type $/ \mathrm{tk} /$, as in $/ \mathrm{t}-\mathrm{kti} /$ 'she remembers', contains a schwa vowel which acts as a syllable peak, thus making this sequence a heavy syllable (i.e. CVC). Based on data drawn from versification, the aim is to examine whether such $\mathrm{CC}$ sequences are treated in Tashlhiyt poetry as heavy syllables, where the second consonant is a coda, or rather as light syllables, where the second consonant is a nucleus.

In Tashlhiyt poetry, specifically songs by Tashlhiyt travelling singers and musicians known as Rrways, ${ }^{24}$ it is common for all the lines of a poem to be sung to the same tune. In other words, the music of a piece of 123

${ }^{24}$ On the music of Rrways (plural of Rrays) and the social background, see Schuyler (1979). 


\section{Rachid Ridouane}

lines is a sequence of 123 repetitions of the same tune. A consequence of this is that all the lines of a piece share the same metre, characterised by specific sequences of a definite number of heavy and light syllables (see Jouad 1983, 1986 and Dell \& Elmedlaoui 1997, 2002 for the parsing of Tashlhiyt verse). A heavy syllable $(\mathrm{H})$ is one that has a coda consonant, while a light syllable (L) lacks a coda consonant. In the piece given in (3), the pattern is LHLLLHLLLLH. The metre is thus composed of 11 syllables, where the second, sixth and eleventh must be heavy and all the others must be light. The text presents selected lines of a well-known poem song by a famous professional Rrays (Mohamed Albensir) in the early 70s, which contains 123 lines (the five lines in (3) correspond to lines $3,5,12,87$ and 99 in the poem). ${ }^{25}$

(3) a. mqar tnt ksis ar disnt nttl

m.qar.tn.tk.si.sar.di.sn.tnt.tl.łab

'even if I feed them on and play with them'

b. han ur gis nkkin amsar ul akssab

ha.nur.gi.un(k).ki.nam.sa.ru.la.ks.sab

'I am neither a purchaser nor an owner'

c. if Jatn ukssab is das ira wajjad

i(f). Jat.nu.ks.sa.bis.da.ri.ra.wa(j).jad

'the owner ate them and looks for more'

d. is a tsllan i wa Jtuk sfid ibidd

i.sat.sl.la.ni.waj.tu.ks.iৎ.di.bidd

'if they listen to Achtou Said (a singer) standing up'

e. mn waHd usttin att ukan ntm33ad

mn.waH.du.st.ti.nat.tu.ka.nn.tm(3).zad

'we have been praising him since 1961'

The same text is given in Table IV in eleven boxes, each corresponding to a metrical syllable. Scansion operates regardless of morphological or syntactic boundaries, as is the case in Tashlhiyt poetic scansion in general (see Jouad 1986). When a coda is the first half of a geminate which straddles a syllable boundary, the syllable may be treated as heavy or light, depending on the needs of the metre (see Dell \& Elmedlaoui 1997, 2002).

The text in (3) contains 55 metrical syllables, 14 of which have consonants as nuclei. What is worthy of note are the voiceless syllables in cells a4, c4, e4, d8 and b10 of Table IV. Let us consider those in column 4. Suppose there were a schwa nucleus associated with the syllabic voiceless obstruents (e.g. [tək] instead of [tk] in 4a) and that this vowel is somehow 'obscured' or 'hidden' by phonetic implementation. The presence of

25 These lines are chosen for illustration because each of them contains a voiceless obstruent-only syllable. The complete text and large audio extracts of the song are available (June 2008) at http://www.azawan.com/tachelhit/albensir/albensir.htm. 


\begin{tabular}{|c|c|c|c|c|c|c|c|c|c|c|c|}
\hline & 1 & 2 & 3 & 4 & 5 & 6 & 7 & 8 & 9 & 10 & 11 \\
\hline & $\mathrm{L}$ & $\mathrm{H}$ & $\mathrm{L}$ & $\mathrm{L}$ & $\mathrm{L}$ & $\mathrm{H}$ & $\mathrm{L}$ & $\mathrm{L}$ & $\mathrm{L}$ & $\mathrm{L}$ & $\mathrm{H}$ \\
\hline a. & $\mathrm{m}$ & qar & tn & $\mathrm{tk}$ & si & вar & di & sn & $\operatorname{tn}(\mathrm{t})$ & $\mathrm{tl}$ & Gab \\
\hline b. & ha & nur & gi & $\mathrm{bn}(\mathrm{k})$ & ki & nam & sa & ви & la & ks & sab \\
\hline c. & $\mathrm{i}\left(\int\right)$ & fat & nu & ks & sa & bis & da & ві & $\mathrm{ra}$ & wa(j) & $\mathrm{jad}$ \\
\hline d. & $\mathrm{i}$ & вat & $\mathrm{sl}$ & la & ni & waf & tu & ks & Gi & di & bidd \\
\hline e. & $\mathrm{mn}$ & wah & $\mathrm{du}$ & st & $\mathrm{ti}$ & nat & tu & $\mathrm{ka}$ & $\mathrm{nn}$ & $\operatorname{tm}(3)$ & $3 \mathrm{ad}$ \\
\hline
\end{tabular}

Table IV

The analysis of the metrical structure of the material in (3).

this schwa should change the weight of these syllables, which would then become heavy (i.e. CVC). But these syllables are scanned as light, as is required by the parsing of this verse, just like the syllable [la] in the corresponding cell in $\mathrm{d} 4$.

Aligning a set of words to a tune is not the preserve of professional singers, and does not systematically imply conscious effort or specialised skills. Rather, native speakers, including children, can also determine whether a set of words and a tune fit together, independently of their musical experience. An illustration of this can be drawn from the numerous examples where children make new words and sing them to the tune of a well-known song or refrain. One such example is given in (4). This text, as performed in the area of Agadir and its suburbs, presents the Tashlhiyt words sung to the refrain of KC and The Sunshine Band Lyrics' That's the way I like it. ${ }^{26}$

(4) a. $\mathrm{t} \int$ jit tswit (aha aha)

t $\int . \int i .(t) t \underline{s}$.wit

'you have enough to eat and to drink'

b. tlsit dzin (aha aha)

tl.si.td. zin

'you wear Jean's trousers'

c. tasit lquq (aha aha)

ta.si.tl.quq

'you have a girlfriend'

d. ma ssul trit (aha aha)

ma.(s)su.lt.rit

'what else do you want?'

In (4), the metrical pattern is LLLH, where the last syllable is heavy and all the others are light. The same text is given in Table V, where each cell corresponds to a metrical syllable.

${ }^{26}$ Extracts of this modified song can be heard in Aslal's one man-show 'Unamir d lkumisir', available (June 2008) at http://aslal.africa-web.org/. 


\begin{tabular}{|c|c|c|c|c|}
\cline { 2 - 5 } \multicolumn{1}{c|}{} & 1 & 2 & 3 & 4 \\
\cline { 2 - 5 } \multicolumn{1}{c|}{} & L & L & L & H \\
\hline a. & t & fi & $(\mathrm{t})$ ts & wit \\
b. & tl & si & td & 3in \\
c. & ta & si & tl & quq \\
d. & ma & su & lt & rit \\
\hline
\end{tabular}

Table $V$

The analysis of the metrical structure of the material in (4).

As stated above, scansion operates regardless of morphological or syntactic boundaries, and some geminates behave as singletons (a3) and others as sequences of two identical consonants (a1). Let us consider the syllables of the first column. As is required by the metrical pattern, all these syllables are light. In $/ \mathrm{t} \mathrm{J} /$, the nucleus is occupied by a voiceless obstruent, while in b1 the syllabic segment is a sonorant. In c1, the syllable nucleus is a vowel. The consonant-only syllables in this column cannot be considered to be heavy syllables (i.e. [təf, təl], rather than attested $[\mathrm{t} f, \mathrm{t}]]$ ), as supposed by the schwa-nucleus theory defended by Coleman. If this were the case, Tashlhiyt speakers would no longer view the text as a succession of well-formed lines with the same metrical pattern. This example suggests that, in performing the operation of aligning Tashlhiyt words to the tune of this refrain, children rely to a great extent on mental abilities which they possess as native speakers of a language in which $/ \mathrm{CC} /$ and $/ \mathrm{CV} /$ are both considered as well-formed light syllables.

2.2.2 Assibilation. The second argument provides additional evidence for the view that two consonants which are not separated by one of the full vowels / $\mathrm{a} \mathrm{i} \mathrm{u} /$ are adjacent at the surface. This is true even of $\mathrm{CC}$ sequences in which the second consonant constitutes a syllable peak. The argument is based on the behaviour of adjacent consonants with respect to the phonological process of assibilation. In the variety of Tashlhiyt spoken in the Anti-Atlas, the dental stops $/ \mathrm{t} d /$ are normally realised as [s $\mathrm{z}$ ] (see Boukous 1994). Examples are given in (5).

(5)

$\begin{array}{lll}\text { /t-i-fawt/ } & \text { [sifaws }] & \text { 'light' } \\ \text { /tili/ } & {[\text { sili] }} & \text { 'ewe' } \\ \text { /ataj/ } & {[\text { asaj] }} & \text { 'tea' } \\ \text { /dari/ } & \text { [zari] } & \text { 'in my home' } \\ / \text { udm/ } & {[\text { uzm] }} & \text { 'face' } \\ \text { /udaj/ } & \text { [uzaj] } & \text { 'Jewish' }\end{array}$

The dental stops maintain their occlusion when they are immediately in contact with a coronal consonant (see also Louali-Raynal 1999). 


$\begin{array}{llll}\text { (6) } / \text { a-drar/ } & \text { [adrar] } & \text { *azrar } & \text { 'hill' } \\ \text { /t-nna/ } & \text { [tnna] } & \text { *snna } & \text { 'she said' } \\ \text { /t-sli/ } & \text { [tsli] } & \text { *ssli } & \text { 'she touched' } \\ \text { /itri } & \text { [itri] } & * \text { isri } & \text { 'star' }\end{array}$

When $/ \mathrm{t} /$ and $/ \mathrm{d} /$ are separated from other coronal consonants by one of the full vowels $/ \mathrm{a} \mathrm{i} \mathrm{u/,} \mathrm{the} \mathrm{assibilation} \mathrm{process} \mathrm{operates,} \mathrm{since} \mathrm{the} \mathrm{target} \mathrm{and}$ the prohibiting consonant are not adjacent. Examples are given in (7a). The forms in (7b), which are morphologically related to the words in (7a), show that $/ \mathrm{t} /$ maintains its occlusion, because of its adjacency to $/ \mathrm{r} /$. This sonorant is syllabic in the two forms in (7b).
a. $\mid \mathrm{t}-\mathrm{i}-\mathrm{r}$ is $/$ [sirii] 'heat' |t-a-rkza/ [sarkza] 'dance'
b. $/$ t-rвa/ [tria] 'it is hot'
|t-rkz| [trkz] 'she dances'

As illustration, consider the form /t-i-rii/ and the morphologically related verb $/ \mathrm{t}$-rва/. In $/ \mathrm{t}$-rва/, the adjacency of $/ \mathrm{t} /$ and $/ \mathrm{r} /$ blocks assibilation. In $\mid \mathrm{t}-\mathrm{i}-\mathrm{r}$ ri $/, \mid \mathrm{t} /$ and $/ \mathrm{r} /$ are no longer adjacent, and assibilation operates, giving [sirri]. Now let us suppose that in /t-ria/, the first two consonants are separated by schwa. According to Coleman's schwa nucleus theory, schwa would be located before the syllabic $/ \mathrm{r} /$ (i.e. [tərsa]). The schwa here should make assibilation possible, since $/ \mathrm{t} /$ and $/ \mathrm{r} /$ are not adjacent. If assibilation took place in /t-rвa/, it would be pronounced as [s(ə)rъa]. But this is not the case, since the dental $/ \mathrm{t} /$ maintains its occlusion in this form. If we postulate the presence of schwa, we must then explain why /a i u/do not obstruct assibilation, as in (7a), while schwa does. This problem does not arise in an analysis in which schwa is not a segment of Tashlhiyt.

The argument developed here concerning assibilation is analogous in principle to that of Dell \& Elmedlaoui (2002). Their argument makes use of regressive devoicing in Imdlawn Tashlhiyt. This Tashlhiyt variety, as well as some other dialects (such as the Haha variety; see Ridouane 1999), has a process of regressive devoicing applying in clusters of adjacent obstruents. In the perfective verb /s-uzf/ 'discover', for instance, the adjacency of $/ \mathbf{z} /$ and $/ \mathrm{f} /$ makes regressive devoicing possible, yielding [z.zu.sf].$^{27}$ The corresponding imperfective form of this verb is [zzuzuf], with a copy of the initial vowel inserted in the final cluster, thus making $|\mathbf{z}|$ and $\mid \mathfrak{f} /$ non-adjacent and regressive devoicing impossible. Again, the assumption that the perfective form contains an epenthetic vowel before the nucleus $\mid \mathrm{f} /$ is problematic. Why does the full vowel obstruct devoicing, while schwa does not?

27 On the gemination of the initial consonant in such forms see Dell \& Elmedlaoui (1989). 


\section{Rachid Ridouane}

A possible alternative to the analysis posited here would be to argue that there is a schwa-epenthesis rule in Tashlhiyt, which is ordered after the maintenance of occlusion in the Anti-Atlas variety and after the regressive devoicing in the Imdlawn variety. But the burden of proof clearly lies on the proponents of such analysis. They have to show that there is a phonological schwa-epenthesis rule that may be ordered with other rules operating in this language. The comparison with Tarifit, which is reported to have a phonological rule of schwa epenthesis (see Dell \& Elmedlaoui 2002 and the references therein), is very instructive. In this dialect, the epenthetic schwa usually patterns as a vowel in the phonology. Consider the examples below, which show that $/ \mathrm{t} /$ spirantises (8a), unless immediately preceded by a dental nasal /n/ (8b, c) (see El Kirat 1987).
a. /ataj/
[äaj]
'tea'
b. $\mid t$-andan-t $/$
[Oandant]
'regret'
c. /1-Hunt/
[lHunt]
'district'

When a vowel, either full (9a) or schwa (9b), separates $/ \mathrm{t} /$ from $/ \mathrm{n} /$, spirantisation operates.

$\begin{array}{lll}\text { (9) a. } / t-a n u-t / & {[\theta \operatorname{anu} \theta]} & \text { 'well' } \\ \text { b. } / 1-\chi \operatorname{dn}-\mathrm{t} / & {[\partial \mathrm{l} \chi \partial \mathrm{dn} \partial \theta]} & \text { 'work' }\end{array}$

Unlike in Tashlhiyt, the surface representations of Tarifit contain a schwa, which, by separating / $\mathrm{t} /$ from the nasal $/ \mathrm{n} /$, makes spirantisation possible.

\section{Summary and future work}

Evidence from phonetic and phonological data converges in support of the claim that Tashlhiyt has words and syllables that contain voiceless obstruents only, without any intervening schwa. Taken together, these results, together with various arguments showing that these long consonantal sequences are organised into a syllable structure (see Dell \& Elmedlaoui 1985, 1988, 2002, Prince \& Smolensky 1993, Clements 1997), provide compelling evidence that in this language a sequence of the type [tk] is a well-formed syllable. As already mentioned, one argument usually presented as evidence showing that consonant-only words are parsed into syllables is related to native linguists' intuitions (this is the case, for instance, for Elmedlaoui (Dell \& Elmedlaoui 1985), Boukous 1987 and Jebbour 1995). As an answer to the question 'how many syllables do the voiceless words in Table I have and how are they parsed?', my own intuitions as a native speaker give the parsings in Table I. While these long consonant sequences seem extremely complex, my intuitions suggest that their syllable structure is quite simple and straightforward in the majority of these forms. 
A question that naturally arises, in view of these parsings, is whether these judgements, if shared by non-linguist native speakers, are based on some surface physical differences perceived by Tashlhiyt native speakers. This question echoes one of the most hotly debated in syllable theory: what are the phonetic correlates of the syllable, if any? A number of phoneticians, from Scripture (1902) and Rousselot (1909) to Rosetti (1963) and Malmberg (1971), consider the syllable merely as a psychological reality with no direct physical correlates. Others, on the other hand, consider the syllable as a physical unit (Sievers 1881, Stetson 1951, Catford 1977). However, according to the extensive literature review by Krakow (1999), efforts to find clear acoustic and physiological correlates of syllables had largely failed by the mid 1980s. The quest has since continued, and a number of more structural accounts have been proposed. According to the Frame/Content theory of MacNeilage (1998: 499), for example, syllables constitute a 'continual rhythmic alternation between an open and a closed mouth (a frame) on the sound production process'. The mouth opens for vowels, which are considered to be syllable nuclei, and closes to varying degrees for the surrounding consonants. Another definition of the syllable has been proposed within the framework of Articulatory Phonology. Syllables are defined as the stable patterns of temporal organisation into which the phonological units (i.e. gestures) coalesce (Browman \& Goldstein 1995). In particular, it has been shown that syllable position plays an important role in shaping articulatory patterns, both in the realisation of the consonants and in the timing relation between units (see Byrd 1994, Browman \& Goldstein 1995).

The framework of Articulatory Phonology provides a way of thinking about the physical properties of syllables that leads to testable hypotheses. Two preliminary studies (Browman et al. 1998, using electromagnetic midsagittal articulometry (EMMA), and Ridouane \& Fougeron 2006, using electropalatography) were conducted within this framework and tested different hypotheses about syllable organisation in Tashlhiyt. Their results, obtained each from one subject, are in agreement. They show that syllable organisation in Tashlhiyt is not reliably reflected in any superficial properties of the articulatory gestures and their relative timing, but rather in the tightness of their co-ordination. Consonant gestures bearing an onset-nucleus relation are more strongly bonded than a heterosyllabic sequence (i.e. less overlap, longer delay between events and more stable co-ordination). These findings, which imply that native speakers' intuitions about syllabification are not based on observable physical differences, present potential arguments against the Frame/ Content theory, which proposes a strong physiological definition of the syllable. Of course, these results are preliminary and need to be confirmed from additional data and subjects. Current and future work should therefore continue to determine whether consonant-only syllables constitute an example in which syllable organisation is a purely abstract property of the phonological structure of an utterance. 


\section{Appendix A}

The twelve items recorded during the acoustic experiment to test for the devoicing of high vowels.

$\begin{array}{ll}\text { [tksit] } & \text { 'you fed on' } \\ \text { [tftit] } & \text { 'you went' } \\ \text { [tktit }] & \text { 'you remembered' } \\ \text { [tss } \chi \text { sit }] & \text { 'you extinguished' } \\ \text { [tssfsit] } & \text { 'you melted' } \\ \text { [tkkiststt] } & \text { 'you took it off' }\end{array}$

$\begin{array}{ll}\text { [sut] } & \text { 'drink it' } \\ {[\text { tsffu } \chi \mathrm{t}]} & \text { 'you excluded' } \\ {\left[\mathrm{t} \int \mathrm{ut}\right]} & \text { 'she drew' } \\ \text { [tutstt] } & \text { 'she hit her' } \\ \text { [tsufft] } & \text { 'you inflated' } \\ \text { [tssukft] } & \text { 'you tore it off' }\end{array}$

\section{Appendix B}

The six additional words and the three voiceless sentences recorded during the PGG experiment.

$\begin{array}{llll}{[\mathrm{ftf}]} & \text { 'crush' } & {[\mathrm{tssft} \chi \mathrm{t}]} & \text { 'you make (someone) roll' } \\ {[\mathrm{tks}]} & \text { 'she feeds on' } & {[\mathrm{tftktstt} \mathrm{tfktstt}]} & \text { 'you sprained it and gave it' } \\ {[\mathrm{ftxt}]} & \text { 'roll it' } & {\left[\mathrm{tssk} \int \mathrm{ftstt} \mathrm{tfktstt}\right]} & \text { 'you dried it and gave it' } \\ ![\mathrm{t} \chi \mathrm{tf}] & \text { 'she stole' } & {[\mathrm{tssk} f \mathrm{ftstt} \mathrm{tft} \chi \mathrm{tstt}]} & \text { 'you dried it and rolled it' } \\ {[\mathrm{tkst}]} & \text { 'you feed on' } & & \end{array}$

\section{REFERENCES}

Angoujard, Jean-Pierre (1997). Théorie de la syllabe : rythme et qualité. Paris: CNRS. Bagemihl, Bruce (1991). Syllable structure in Bella Coola. LI 22. 589-646.

Boersma, Paul (2001). Praat: a system for doing phonetics by computer. Glot International 5. 341-345.

Boukous, Mohamed (1987). Phonotactique et domaine prosodique en berbère (parler tachelhit d'Agadir, Maroc). $\mathrm{PhD}$ dissertation, Université Paris 8.

Boukous, Mohamed (1994). Variation phonique et compétence globale: le cas du parler d'Agadir. Rabat: Publications de la Faculté des Lettres et des Sciences Humaines.

Boukous, Mohamed (1995). Sociétés, langues et cultures au Maroc: enjeux symboliques. Rabat: Publications de la Faculté des Lettres et des Sciences Humaines.

Boukous, Mohamed (2000). L'amazighe: perte irréversible ou changement linguistique? In Salem Chaker \& Anderzej Zaborski (eds.) Études berbères et chamitosémitiques : mélanges offerts à Karl-G. Prasse. Paris: Peeters. 43-59.

Browman, Catherine P. \& Louis Goldstein (1995). Dynamics and Articulatory Phonology. In Robert F. Port \& Timothy van Gelder (eds.) Mind as motion : explorations in the dynamics of cognition. Cambridge, Mass.: MIT Press. 175-193.

Browman, Catherine P., Louis Goldstein, Douglas Honorof, Abdelkrim Jebbour \& Elisabeth Selkirk (1998). Gestural organization underlying syllable structure. Paper presented at Current Trends in Phonology II, Royaumont.

Byrd, Dani (1994). Articulatory timing in English consonant sequences. PhD dissertation, University of California, Los Angeles.

Catford, J. C. (1977). Fundamental problems in phonetics. Edinburgh: Edinburgh University Press. 
Chaker, Salem (1992). Une décennie d'études berbères (1980-1990). Bibliographie critique: langue, littérature, identité. Algiers: Bouchène.

Chaker, Salem (1994). Chleuh (linguistique/littérature). In Gabriel Camps (ed.) Encyclopédie berbère. Aix-en-Provence: Edisud. 1926-1933.

Clements, G. N. (1997). Berber syllabification: derivations or constraints? In Iggy Roca (ed.) Derivations and constraints in phonology. Oxford: Clarendon. 289-330.

Coleman, John (1996). Declarative syllabification in Tashlhit Berber. In Durand \& Laks (1996). 177-218.

Coleman, John (1999). The nature of vocoids associated with syllabic consonants in Tashlhiyt Berber. In Ohala et al. (1999). 735-738.

Coleman, John (2001). The phonetics and phonology of Tashlhiyt Berber syllabic consonants. Transactions of the Philological Society 99. 29-64.

Dell, François \& Mohamed Elmedlaoui (1985). Syllabic consonants and syllabification in Imdlawn Tashlhiyt Berber. Fournal of African Languages and Linguistics 7. 105-130.

Dell, François \& Mohamed Elmedlaoui (1988). Syllabic consonants in Berber: some new evidence. Fournal of African Languages and Linguistics 10. 1-17.

Dell, François \& Mohamed Elmedlaoui (1989). Clitic ordering, morphology and phonology in the verbal complex of Imdlawn Tashlhiyt Berber: part I. Langues Orientales Anciennes Philologie et Linguistique 2. 165-194.

Dell, François \& Mohamed Elmedlaoui (1996). Nonsyllabic transitional vocoids in Imdlawn Tashlhiyt Berber. In Durand \& Laks (1996). 219-246.

Dell, François \& Mohamed Elmedlaoui (1997). La syllabation et les géminées dans la poésie berbère du Maroc (dialecte chleuh). Cahiers de Grammaire 22. 1-95.

Dell, François \& Mohamed Elmedlaoui (2002). Syllables in Tashlhiyt Berber and in Moroccan Arabic. Dordrecht: Kluwer.

Durand, Jacques \& Bernard Laks (eds.) (1996). Current trends in phonology : models and methods. 2 vols. Salford: ESRI.

El Kirat, Yamina (1987). Spirantization in the Beni Iznassen dialect: diachrony and synchrony. Mémoire de D.E.S.S., Université Mohammed V, Rabat.

Elmedlaoui, Mohamed (1985). Le parler berbère chleuh d'Imdlawn (Maroc) : segments et syllabation. $\mathrm{PhD}$ dissertation, Université Paris 8.

Elmedlaoui, Mohamed (1999). Principes d'orthographe berbère en graphie arabe et latine. Oujda: Publications de la Faculté des Lettres et des Sciences Humaines d'Oujda.

Elmedlaoui, Mohamed (2000). L'arabe marocain, un lexique sémitique inséré sur un fond grammatical berbère. In Salem Chaker \& Andrzej Zaborski (eds.) Études berbères et chamito-sémitiques. Paris: Peeters. 155-188.

Fougeron, Cécile \& Elisabeth Delais-Roussarie (2004). Fais_en à Fez_en parlant: étude comparative de la liaison et de l'enchaînement. In Bernard Bel \& Isabelle Marlien (eds.) Actes des XXVes Fournés d'Éude sur la Parole. Fès, Morocco: AFCP. 212-225.

Fujimoto, Masako, Emi Murano, Seiji Niimi \& Shigeru Kiritani (2002). Differences in glottal opening pattern between Tokyo and Osaka dialect speakers: factors contributing to vowel devoicing. Folia Phoniatrica et Logopaedica 54. 133-143.

Galand, Lionel (1988). Le berbère. In Jean Perrot (ed.) Les langues dans le monde ancien et moderne. Part 3 : Les langues chamito-sémitiques. Paris: CNRS. 207-242.

Greenberg, Joseph H. (1969). Some generalizations concerning initial and final consonant sequences. Linguistics 18 . 5-34.

Hall, Nancy (2003). Gestures and segments : vowel intrusion as overlap. PhD dissertation, University of Massachusetts, Amherst.

Hall, Nancy (2006). Cross-linguistic patterns of vowel intrusion. Phonology 23. 387-429.

Hyman, Larry M. (1985). A theory of phonological weight. Dordrecht: Foris. 


\section{Rachid Ridouane}

Jebbour, Abdelkrim (1995). Mores et poids prosodique en berbère. Langues Orientales Anciennes : Philologie et Linguistique 5-6. 167-192.

Jouad, Hassan (1983). Les éléments de la versification en berbère marocain tamazight et tachelhit. $\mathrm{PhD}$ dissertation, Université Paris 3.

Jouad, Hassan (1986). Mètres et rythmes de la poésie orale en berbère marocain. Cahiers de Poétique Comparée 12. 105-127.

Jun, S.-A. \& Mary Beckman (1993). A gestural overlap analysis of vowel devoicing in Japanese and Korean. Paper presented at the 67th Annual Meeting of the Linguistic Society of America, Los Angeles.

Kenstowicz, Michael (1994). Phonology in generative grammar. Cambridge, Mass. \& Oxford: Blackwell.

Kondo, Mariko (2005). Syllable structure and its acoustic effects on vowels in devoicing environments. In Jeroen van de Weijer, Kensuke Nanjo \& Tetsuo Nishihara (eds.) Voicing in fapanese. Berlin \& New York: Mouton de Gruyter. 229-245.

Krakow, Rena A. (1999). Physiological organization of syllables: a review. $\mathscr{F P h} 27$. $23-54$.

Levin, Juliette (1985). A metrical theory of syllabicity. PhD dissertation, MIT.

Löfqvist, Anders \& Hirohide Yoshioka (1980). Laryngeal activity in Swedish obstruent clusters. FASA 68. 792-801.

Louali, Naïma \& Gilbert Puech (2000). Etude sur l'implémentation du schwa pour quatre locuteurs berbères de tachelhit. Actes des 23 e Fournées d'Études sur la Parole. Aussois. 25-28.

Louali-Raynal, Naïma (1999). La spirantisation en berbère. Paper presented at the 9th Italian Meeting of Afro-Asiatic (Hamito-semitic) Linguistics, Trieste.

Macmillan, Neil A. \& C. Douglas Creelman (1991). Detection theory : a user's guide. Cambridge: Cambridge University Press.

MacNeilage, Peter F. (1998). The frame/content theory of evolution of speech production. Behavioral and Brain Sciences 21. 499-511.

Malmberg, Bertil (1971). Voyelle, consonne, syllabe, mot. In Bertil Malmberg Phonétique générale et romane: études en allemand, anglais, espagnol et français. Mouton: The Hague \& Paris. 131-140.

Mo, Yoonsook (2007). Temporal, spectral evidence of devoiced vowels in Korean. In Trouvain \& Barry (2007). 445-448.

Nathan, Geoffrey S. (2004). Review of Dell \& Elmedlaoui (2002). Fournal of the International Phonetic Association 34. 215-217.

Ohala, John J. (1997). Aerodynamics of phonology. Proceedings of the 4th Seoul International Conference on Linguistics [SICOL]. Seoul: Linguistic Society of Korea. 92-97.

Ohala, John J., Yoko Hasegawa, Manjari Ohala, Daniel Granville \& Ashlee C. Bailey (eds.) (1999). Proceedings of the 14th International Congress of Phonetic Sciences. Berkeley: Department of Linguistics, University of California, Berkeley.

Ouakrim, Omar (1993). Fonética y fonologia del Bereber. PhD dissertation, Universitat Autònoma de Barcelona.

Podeur, John (1995). Textes berbères des Ait Souab (Anti-Atlas, Maroc). Aix-enProvence: Edisud.

Prince, Alan \& Paul Smolensky (1993). Optimality Theory : constraint interaction in generative grammar. Ms, Rutgers University \& University of Colorado, Boulder. Published 2004, Malden, Mass. \& Oxford: Blackwell.

Puech, Gilbert \& Naima Louali (1999). Syllabification in Berber: the case of Tashlhiyt. In Ohala et al. (1999). 747-750.

Ridouane, Rachid (1999). La spirantisation dans un parler berbère du Maroc (parler chleuh de Haha). Diplôme d'Etudes Approfondies, Université Paris 3.

Ridouane, Rachid (2003). Suites de consonnes en berbère : phonétique et phonologie. $\mathrm{PhD}$ dissertation, Université Paris 3. 
Ridouane, Rachid (2007). Gemination in Tashlhiyt Berber: an acoustic and articulatory study. Fournal of the International Phonetic Association 37. 119-142.

Ridouane, Rachid \& Cécile Fougeron (2006). Organisation syllabique dans des suites de consonnes en berbère: quelles évidences phonétiques? Actes des 26e Fournées d'Études sur la Parole. Dinard. 371-374.

Ridouane, Rachid, Susanne Fuchs \& Phil Hoole (2006). Laryngeal adjustments in the production of voiceless obstruent clusters in Berber. In Jonathan Harrington \& Maria Tabain (eds.) Speech production: models, phonetic processes, and techniques. New York: Psychology Press. 275-301.

Ridouane, Rachid, Phil Hoole \& Susanne Fuchs (2007). Laryngeal behaviour in voiceless words and sentences: a photoelectroglottographic study. In Trouvain \& Barry (2007). 2049-2052.

Rosetti, A. (1963). Sur la théorie de la syllabe. The Hague: Mouton.

Rousselot, P.-J. (1909). Principes de phonétique expérimentale. Paris: Welter.

Sawashima, Masayuki (1971). Devoicing of vowels. Annual Bulletin of the Research Institute of Logopedics and Phoniatrics 5. 7-13.

Schuyler, Philip D. (1979). A repertory of ideas: the music of the 'rwais', Berber professional musicians from Southwestern Morocco. PhD dissertation, University of Washington.

Scripture, Edward (1902). The elements of experimental phonetics. New York: Charles Scribner's Sons.

Shahin, Kimary \& Susan J. Blake (2004). A phonetic study of schwa in St'àt'imcets (Lillooet Salish). In Donna B. Gerdts \& Lisa Matthewson (eds.) Studies in Salish linguistics in honor of M. Dale Kinkade. Missoula: University of Montana. 311-327.

Sievers, Eduard (1881). Grundzüge der Phonetik. Leipzig: Breitkopf \& Härtel.

Stetson, Raymond H. (1951). Motor phonetics : a study of speech movements in action. Amsterdam: North-Holland.

Trouvain, Jürgen \& William J. Barry (eds.) (2007). Proceedings of the 16th International Congress of Phonetic Sciences. Saarbrücken: Universität des Saarlandes.

Tsuchida, Ayako (1997). The phonetics and phonology of Gapanese vowel devoicing. PhD dissertation, Cornell University.

Tsuchida, Ayako (2001). Japanese vowel devoicing: cases of consecutive devoicing environments. Fournal of East Asian Linguistics 10. 225-245.

Yoshioka, Hirohide (1981). Laryngeal adjustment in the production of the fricative consonants and devoiced vowels in Japanese. Phonetica 38. 236-351.

Yoshioka, Hirohide, Anders Löfqvist \& Hajime Hirose (1981). Laryngeal adjustments in the production of consonant clusters and geminates in American English. $\mathcal{F} A S A$ 70. 1615-1623.

Zec, Draga (1988). Sonority constraints on prosodic structure. PhD dissertation, Stanford University.

Zec, Draga (1995). Sonority constraints on syllable structure. Phonology 12. 85-129. 